NASA/TM-1998-208805

Flow/Damage Surfaces for Fiber-Reinforced Metals Having Different Periodic Microstructures

Cliff J. Lissenden

Pennsylvania State University, University Park, Pennsylvania

Steven M. Arnold

Lewis Research Center, Cleveland, Ohio

Saiganesh K. Iyer

Pennsylvania State University, University Park, Pennsylvania 
Since its founding, NASA has been dedicated to the advancement of aeronautics and space science. The NASA Scientific and Technical Information (STI) Program Office plays a key part in helping NASA maintain this important role.

The NASA STI Program Office is operated by Langley Research Center, the Lead Center for NASA's scientific and technical information. The NASA STI Program Office provides access to the NASA STI Database, the largest collection of aeronautical and space science STI in the world. The Program Office is also NASA's institutional mechanism for disseminating the results of its research and development activities. These results are published by NASA in the NASA STI Report Series, which includes the following report types:

- TECHNICAL PUBLICATION. Reports of completed research or a major significant phase of research that present the results of NASA programs and include extensive data or theoretical analysis. Includes compilations of significant scientific and technical data and information deemed to be of continuing reference value. NASA's counterpart of peerreviewed formal professional papers but has less stringent limitations on manuscript length and extent of graphic presentations.

- TECHNICAL MEMORANDUM. Scientific and technical findings that are preliminary or of specialized interest, e.g., quick release reports, working papers, and bibliographies that contain minimal annotation. Does not contain extensive analysis.

- CONTRACTOR REPORT. Scientific and technical findings by NASA-sponsored contractors and grantees.
- CONFERENCE PUBLICATION. Collected papers from scientific and technical conferences, symposia, seminars, or other meetings sponsored or cosponsored by NASA.

- SPECIAL PUBLICATION. Scientific, technical, or historical information from NASA programs, projects, and missions, often concerned with subjects having substantial public interest.

- TECHNICAL TRANSLATION. Englishlanguage translations of foreign scientific and technical material pertinent to NASA's mission.

Specialized services that complement the STI Program Office's diverse offerings include creating custom thesauri, building customized data bases, organizing and publishing research results ... even providing videos.

For more information about the NASA STI Program Office, see the following:

- Access the NASA STI Program Home Page at http://www.sti.nasa.gov

- E-mail your question via the Internet to help@sti.nasa.gov

- Fax your question to the NASA Access Help Desk at (301) 621-0134

- Telephone the NASA Access Help Desk at (301) 621-0390

- Write to:

NASA Access Help Desk

NASA Center for AeroSpace Information 7121 Standard Drive

Hanover, MD 21076 
NASA/TM-1998-208805

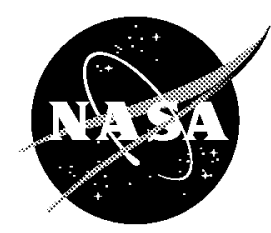

Flow/Damage Surfaces for Fiber-Reinforced Metals Having Different Periodic Microstructures

\author{
Cliff J. Lissenden \\ Pennsylvania State University, University Park, Pennsylvania \\ Steven M. Arnold \\ Lewis Research Center, Cleveland, Ohio \\ Saiganesh K. Iyer \\ Pennsylvania State University, University Park, Pennsylvania
}

National Aeronautics and

Space Administration

Lewis Research Center 


\section{Acknowledgments}

We would like to thank Dr. T.E. Wilt for his assistance in extending MAC/GMC so as to conduct flow surface probing. The first author gratefully acknowledges the support of the NASA Lewis Research Center, grant NCC3-481.

Available from

NASA Center for Aerospace Information 7121 Standard Drive

Hanover, MD 21076

Price Code: A03
National Technical Information Service 5285 Port Royal Road Springfield, VA 22100 Price Code: A03 


\title{
FLOW/DAMAGE SURFACES FOR FIBER-REINFORCED METALS HAVING DIFFERENT PERIODIC MICROSTRUCTURES
}

\author{
Cliff J. Lissenden, and Saiganesh K. Iyer \\ Pennsylvania State University \\ University Park, Pennsylvania 16802 \\ Phone: (814) 863-5754, FAX: (814) 863-6031 \\ email: cjlesm@psu.edu \\ and \\ Steven M. Arnold, \\ National Aeronautics and Space Administration \\ Lewis Research Center \\ Cleveland, Ohio 44135
}

SUMMARY

Flow/damage surfaces can be defined in terms of stress, inelastic strain rate, and internal variables using a thermodynamics framework. A macroscale definition relevant to thermodynamics and usable in an experimental program is employed to map out surfaces of constant inelastic power in various stress planes. The inelastic flow of a model silicon carbide/titanium composite system having rectangular, hexagonal, and square diagonal fiber packing arrays subjected to biaxial stresses is quantified by flow/damage surfaces that are determined numerically from micromechanics, using both finite element analysis and the generalized method of cells. Residual stresses from processing are explicitly included and damage in the form of fiber-matrix debonding under transverse tensile and/or shear loading is represented by a simple interface model. The influence of microstructural architecture is largest whenever fiber-matrix debonding is not an issue; for example in the presence of transverse compressive stresses. Additionally, as the fiber volume fraction increases, so does the effect of microstructural architecture. With regard to the micromechanics analysis, the overall inelastic flow predicted by the generalized method of cells is in excellent agreement with that predicted using a large number of displacement-based finite elements.

\section{INTRODUCTION}

The advent of man-made fiber-reinforced composite materials some forty years ago enabled the design of more efficient structures and greatly expanded the domain of engineered materials. Recent developments in the processing of unidirectional metal matrix composites (MMCs) provide new opportunities for engineers and materials scientists to tailor microstructural architecture for specific applications. For example, placing individual fibers in photo-etched grooves in foils of matrix material results in a very uniform microstructure. Since the grooves hold the fiber in place during consolidation, the microstructure can be engineered by simply specifying the foil thickness and groove pattern. Consequently, this paper addresses the effect that various microstructures have on the overall inelastic material response in the presence of multiaxial stress states.

This research merges and builds upon two recent publications on unidirectional composites; one dealing with different microstructural architectures subjected to uniaxial loadings (Arnold et al., 1996a) and the other with macroscale flow/damage surfaces (Lissenden and Arnold, 1997a) given a fixed architecture. Hence, a brief summary of each follows, after which the objectives of the current work are enumerated.

Arnold et al. (1996a) begins with an extensive survey of the literature dealing with the effects of fiber shape and distribution on the response of composites. The generalized method of cells (Paley and Aboudi, 1992) was summarized and then used to predict the response of a silicon carbide/titanium system ( $\mathrm{SiC} / \mathrm{Ti}$ ). The results presented demonstrate the relative effects of fiber arrangement and shape on the axial and transverse stress-strain and creep responses for both strong and weak fiber/matrix interfacial bonds. Fiber arrangements considered include rectangular, square, square diagonal, and hexagonal periodic arrays as well as a random arrangement. Circular, square, and 
cross-shaped fiber cross-sections were studied as were the effects of fiber volume fraction and strain rate on the stress-strain response. Additionally, the stress-strain and creep responses of "hybrid" composites (those with different size fibers having different arrangements and bond strengths) were investigated to determine the feasibility of using this approach to enhance the transverse toughness and creep resistance.

Lissenden and Arnold (1997a) addressed theoretical and experimental issues regarding constitutive model development for anisotropic heterogeneous materials using micromechanics in lieu of actual experimental data. The generalized method of cells with four subcells, arranged to represent a square array of fibers was used to predict the multiaxial response of MMCs in terms of overall flow/damage surfaces (i.e., those incorporating matrix viscoplasticity and fiber/matrix debonding) in three different stress planes. The flow/damage surfaces were shown to have their centers offset from the origin by residual stresses and their shape altered by debonding. The normality condition was shown to be reasonably well satisfied for initial surfaces of constant inelastic power (or in this case dissipation) in the presence of fiber-matrix debonding. Results indicated which types of flow/damage surfaces should be characterized and what loading histories applied to obtain the most meaningful experimental data for guiding theoretical model development and verification. This work differed from the extensive studies of plasticity in MMCs conducted by Dvorak and coworkers (summarized by Dvorak, 1991), in that different definitions of rate-dependent flow and the effects of fiber-matrix debonding were addressed by Lissenden and Arnold (1997a).

Herein we will demonstrate, using micromechanics, the influence that the continuously reinforced periodic microstructures shown in figure 1 (namely rectangular, hexagonal, and square diagonal fiber packing arrays) have on overall flow/damage surfaces in the axial-transverse $\left(\sigma_{11}-\sigma_{22}\right)$, transverse-transverse $\left(\sigma_{22}-\sigma_{33}\right)$, axial-shear $\left(\sigma_{11}-\sigma_{12}\right)$, and transverse-shear $\left(\sigma_{22}-\sigma_{12}\right)$ stress planes. Both a displacement-based finite element analysis (FEA) and the generalized method of cells (GMC) micromechanics approach are employed. Since the material response is in general viscoplastic, we will consider flow surfaces (typically important at elevated temperature), which are geometrically analogous to yield surfaces (typically important at room temperature). Furthermore, silicon carbide/ titanium ( $\mathrm{SiC} / \mathrm{Ti}$ ) composites exhibit a weak bond between the constituents and this damage mode, when active, can greatly affect the overall material response. The effects of damage are included in the definition of flow surfaces, hence the name flow/damage surfaces. We will pay particular attention to definitions which indicate a prescribed level of inelasticity or damage, in an attempt to balance theoretical and experimental considerations. Sometimes results for the strong bond case (which is fictitious for current $\mathrm{SiC} / \mathrm{Ti}$ systems) are shown in order to demonstrate how fiber/matrix debonding influences the predicted overall inelasticity.

MMCs are anticipated to be typically used in elevated temperature environments. Unless stated otherwise, the results presented are for a TIMETAL-21S titanium matrix reinforced by a 35 percent fiber volume content of continuous SCS-6 fibers. This unidirectional SiC/Ti system is taken as our model material system (see Arnold and Castelli, 1995). Two fairly extreme temperatures are considered; 23 and $650{ }^{\circ} \mathrm{C}$ (where time-dependent effects dominate the titanium matrix). The fiber response is taken to be linear elastic and temperature-independent, while the matrix response is elastic-viscoplastic (Arnold et al., 1996b and c) and highly temperature-dependent as illustrated in figure 2 . Note that the protective fiber coatings used to reduce fiber strength degradation (associated with chemical reactions with the matrix during processing) result in a weak bond to the matrix. A discussion of modeling this weak bond and the viscoplastic matrix response is postponed until Section III. Finally, as we are interested in surfaces in prescribed stress planes, all loadings are stress controlled. An equivalent stress rate, $\sqrt{\dot{\sigma}_{I} \dot{\sigma}_{I}}$, of $2 \mathrm{MPa} / \mathrm{sec}$ is used in all cases, where $\sigma_{I}$ is the contracted stress tensor and $I=1,2, \ldots, 6$.

In the next section (II) we review the theoretical framework and basic concepts applicable to inelastic flow in MMCs. Flow surface definitions and factors that influence flow are discussed and an appendix (A) provides a continuum example. The FEA and GMC micromechanics models are introduced along with the constituent constitutive models in Section III. The stress-strain response and inelastic power-time response for different microstructural architectures are presented in Section IV. A related appendix (B) discusses the accuracy of the FEA and GMC models. Finally, Section $\mathrm{V}$ presents the effects of microstructure and fiber-matrix debonding on macroscale flow/damage surfaces in four different stress planes at 23 and $650^{\circ} \mathrm{C}$. Section VI provides a closure for the paper.

\section{INELASTIC FLOW}

Our subject is the inelastic multiaxial response of MMCs for applications in elevated temperature environments. Hence, the viscoplasticity of anisotropic composite materials susceptible to internal damage must be addressed. From the viewpoint of a structural analyst investigating complex components, a macroscale continuum model is 
preferred due to its numerical efficiency relative to alternative micromechanics analyses. However, such a continuum model is not currently available; nor are the experimental results that are necessary to develop such a model. Thus, in the present study we will utilize a theoretical framework appropriate for continuum modeling to guide us and employ two micromechanics models to simulate the required experiments numerically, so as to understand the theoretical and experimental implications and/or assumptions necessary in either a macro (continuum) or micromechanics based approach.

\section{II.1. Theoretical Framework}

The theoretical considerations used in this paper are based on an energy balance. The primary variables at any point are the Cauchy stress tensor, $\sigma_{i j}$, the internal stress tensor, $\alpha_{i j}$, and temperature, $T$. Other internal state variables could also be defined and used if we were so motivated. The current values of these variables can be used to define the Gibbs thermodynamic potential, $G=G\left(\sigma_{i j}, \alpha_{i j}, D_{i j}, T\right)$, where $D_{i j}$ is the preferred direction tensor formed by the self product of the unit vector denoting the fiber direction. Conjugate to these variables are the total strain tensor, $\varepsilon_{i j}$, the internal strain tensor, $A_{i j}$, and the entropy, $S$,

$$
\varepsilon_{i j}=-\frac{\partial G}{\partial \sigma_{i j}}, \quad A_{i j}=-\frac{\partial G}{\partial \alpha_{i j}}, \quad S=-\frac{\partial G}{\partial T}
$$

Our basis is that the total work performed on the system must be equal to the sum of the stored energy and the energy dissipated, where the stored energy includes an elastic component as well as an inelastic component associated with the internal state. Thus, the dissipation potential, $\Omega=\Omega\left(\sigma_{i j}, \alpha_{i j}, D_{i j}, T\right)$, can be defined to be $\sigma_{i j} \dot{\varepsilon}_{i j}^{I}-\alpha_{i j} \dot{A}_{i j}$.

The associated flow law (for the inelastic strain rate) and evolution equations (for the internal strain rate) are given by normality,

$$
\dot{\varepsilon}_{i j}^{I}=-\frac{\partial \Omega}{\partial \sigma_{i j}}, \quad \dot{A}_{i j}=\frac{\partial \Omega}{\partial \alpha_{i j}}
$$

and

$$
\dot{\alpha}_{i j}=Q_{i j k l}^{-1} \dot{A}_{k l}
$$

where

$$
Q_{i j k l}=-\frac{\partial^{2} G}{\partial \alpha_{i j} \partial \alpha_{k l}}
$$

and $Q_{i j k l}$ is called the internal compliance operator (Arnold and Saleeb, 1994). Thus, once the functional dependencies of the Gibbs and dissipation potentials have been determined, all of the variables are known by simple differentiation. Let us now assume that the dissipation potential can be written in terms of two scalar functions, $\Omega=\Omega(F, H)$, where $F$ depends on the deviatoric effective stress, $\Sigma_{i j}$, and $H$ depends only on the internal stress (Robinson and Ellis, 1986). The deviatoric effective stress is the difference between the deviatoric Cauchy stress and the deviatoric internal stress. Now the flow law can be written,

$$
\dot{\varepsilon}_{i j}^{I}=\frac{\partial \Omega}{\partial F} \frac{\partial F}{\partial \sigma_{i j}} .
$$

Thus, the direction of the inelastic strain rate vector is normal to surfaces having $F=$ constant. However, if it is true that the normality condition is not satisfied in MMCs, as indicated by Nigam et al. (1994a,b) for boron/aluminum, then it becomes necessary to develop a nonassociated flow law and evolution equations. We return to this issue at the end of Appendix A. 


\section{II.2. Surface Definitions}

The concept of a yield surface is well known in rate-independent plasticity, even if no one definition of yielding has been universally adopted. The most common definitions employed are the proportional limit, a small (usually 5 to $20 \mu \mathrm{m} / \mathrm{m}$ ) offset strain, a back-extrapolation, and a large (usually $2000 \mu \mathrm{m} / \mathrm{m}$ ) offset strain. For rate-dependent plasticity (viscoplasticity), the concept of a strict yield surface breaks down as stress states outside the yield surface are accessible (since no consistency condition applies). Thus the need for geometrically analogous, thermodynamically based, flow surface definitions. At least two different rate-dependent definitions have been proposed for monolithic materials (Clinard and Lacombe, 1988);

(1) surfaces of constant dissipation rate (SCDRs), defined by $\sigma_{i j} \dot{\varepsilon}_{i j}^{I}-\alpha_{i j} \dot{A}_{i j}$ and

(2) surfaces of constant inelastic strain rate (SCISRs), defined by $\sqrt{\dot{\varepsilon}_{i j}^{I} \dot{\varepsilon}_{i j}^{I}}$.

These definitions can also be applied to composite materials. However, one needs to be careful when using micromechanics as the inelastic strain is an eigenstrain and consequently;

$$
\begin{aligned}
& \bar{\sigma}_{i j} \dot{\bar{\varepsilon}}_{i j}^{I} \neq \frac{1}{V} \int_{V} \sigma_{i j} \dot{\varepsilon}_{i j}^{I} d V \\
& \dot{\bar{\varepsilon}}_{i j}^{I} \dot{\bar{\varepsilon}}_{i j}^{I} \neq \frac{1}{V} \int_{V} \dot{\varepsilon}_{i j}^{I} \dot{\bar{\varepsilon}}_{i j}^{I} d V
\end{aligned}
$$

where an over-bar indicates a macroscale quantity and $V$ is the total volume of the representative volume element. The difference is due to the existence of residual stresses, at least some of which are associated with stored elastic energy. Being an additive quantity, the overall dissipation potential can be taken to be the volume average of the local dissipation potentials (Suquet, 1987), and from a theoretical standpoint that is what we would like to quantify. However, it is indeterminate experimentally because the local (internal) variables are unknown and not measurable. This issue is dealt with more completely by Lissenden et al. (1998). Here let us define another type of flow surface using experimentally measurable macroscopic quantities, $\bar{\sigma}_{i j} \dot{\bar{\varepsilon}}_{i j}^{I}$, that are available from both micromechanics and macroscale models. We will call them surfaces of constant inelastic power (SCIPs). This is in fact the nomenclature that should have been used by Lissenden and Arnold (1997a) instead of the term initial SCDRs. The actual difference between SCIPs and SCDRs depends on many factors, but as shown in figure 3 for transverse tensile loading, it can be substantial.

Lissenden and Arnold (1997a) demonstrated, using micromechanics, that the direction of the overall inelastic strain rate vector can differ significantly from the outward normal of a SCISR. Whereas, for the stress planes considered, the direction of the overall inelastic strain rate vector was reasonably close to the outward normal of the SCDRs (actually SCIPs) ${ }^{1}$ considered. SCISRs, however, are certainly more amenable to experimental methods than are SCDRs, and may be more amenable than SCIPs given that stress quantities are not included in the definition. For macroscale continuum theories it is not possible to distinguish between SCDRs and SCIPs. A macroscale continuum example is given in Appendix A.

\section{II.3. Factors Influencing Flow}

Many factors influence inelastic flow in metallic materials. Certainly, temperature and loading rate as well as the past loading history can be important in many metals. Additionally, microstructural architecture, degree of

${ }^{1}$ Note that for a near virgin state, SCDRs and SCIPs are nearly the same given $\alpha_{i j} \approx 0$, but as incleastic flow occurs $\left(\alpha_{i j} \neq 0\right)$ they will diverge. 
anisotropy, fiber-matrix bond strength, and damage influence flow in composites. Other factors, such as the stress plane, definition, and target value influence how flow is represented. Lissenden and Arnold (1997b) illustrated the effects of many of these factors. The current paper focuses on the influence of microstructural architecture and fibermatrix bond strength. We consider repeating microstructures, specifically ones having rectangular, hexagonal, and square diagonal fiber packing arrays as shown in figure 1 . The rectangular array has an aspect ratio, $R=a / b$. For the special case of a square array, $R=1$. Additionally, we consider strong and weak fiber-matrix bonding. Our definition of strong is that there is no discontinuity in the displacement field at the interface. Likewise, weak means that the interface can transmit a finite traction before debonding causes the fiber and matrix to separate.

\section{MICROMECHANICS}

Biaxial experiments on unidirectional continuous-fiber reinforced $\mathrm{SiC} / \mathrm{Ti}$ in the axial-transverse $\left(\sigma_{11}-\sigma_{22}\right)$, transverse-transverse $\left(\sigma_{22}-\sigma_{33}\right)$, axial-shear $\left(\sigma_{11}-\sigma_{12}\right)$, and transverse-shear $\left(\sigma_{22}-\sigma_{12}\right)$ stress planes were simulated numerically using micromechanics. Initial overall (macroscale) flow/damage surfaces were mapped out by a sequence of stress-controlled proportional loading probes at different angles in a prescribed stress plane as shown in figure 4 . The two nonzero stress rate components were calculated to be the cosine and sine of the equivalent stress rate $(2 \mathrm{MPa} / \mathrm{sec})$. Each probe started at the origin and continued until the inelastic power target value had been reached, after which the material was returned to its virgin state, the probe angle increased (usually by $5^{\circ}$ ), and the next probe conducted; until the entire stress plane $\left(0 \rightarrow 360^{\circ}\right)$ had been probed. For surface determinations at room temperature thermal residual stresses were accounted for by cooling the composite from a stress-free temperature of $815^{\circ} \mathrm{C}$ in $2 \mathrm{hr}$. These simulations were conducted using both FEA and GMC, with the specifics described below.

\section{III.1. Finite Element Analysis}

The commercial FEA program ABAQUS (HKS,1995) was used to determine the response of the microstructures of interest (fig. 1). Each microstructure can be represented by a repeating unit cell that has two planes of symmetry. Thus, it is only necessary to analyze a quarter of each unit cell. Coarse and fine discretizations of one quarter of the repeating unit cell for both square and square diagonal arrays are shown in figure 5. Only strongly bonded $\mathrm{SiC} / \mathrm{Ti}$ was considered using FEA for determining SCIPs. Generalized plane strain triangular elements formulated by Lissenden and Herakovich (1995), and implemented into ABAQUS through a UEL subroutine, were used for modeling the repeating unit cell. These triangular elements have an extra node that is common to all elements in the mesh. The degree of freedom in the 1-direction (axial) at this common node is what makes this a generalized plane strain element. Furthermore, warping of the 23-plane permits axial-shear loading to be simulated. Overall inelastic strain components were calculated as the difference between the total strain components, found by volumetric averaging, and the elastic strain, found from the overall stress (volumetric average) and elastic properties.

The boundary conditions applied to each FEA mesh are illustrated schematically in figure 6 . To maintain compatibility with the adjacent unit cells, multipoint constraints (MPCs) were applied on the edges that are in contact with adjacent unit cells. For example, MPCs were applied along the right edge such that the edge remains straight. Stress control loading was simulated by applying concentrated forces at the nodes along an appropriate edge; except for axial loading, where a concentrated force was applied to the common node, which is shown in figure 6 . Details of the applied loadings are summarized in table $\mathrm{I}$.

\section{III.2. Generalized Method of Cells}

The generalized method of cells (GMC) (Paley and Aboudi, 1992; Aboudi, 1995) is an approximate analytical micromechanics model that extends the original method of cells (Aboudi, 1991) to an arbitrary number of subcells, permitting the study of different microstructures. The reader is referred to Aboudi (1995) for the derivation of the detailed equations of GMC. The primary equations of GMC relate to standard micromechanics equations as follows. 


$$
\begin{aligned}
& \bar{\varepsilon}_{i j}=\left\langle\left\langle\varepsilon_{i j}(x)\right\rangle\right\rangle, \quad \bar{\varepsilon}=\frac{1}{d h l} \sum_{\alpha=1}^{N_{\alpha}} \sum_{\beta=1}^{N_{\beta}} \sum_{\gamma=1}^{N_{\gamma}} d_{\alpha} h_{\beta} I_{\gamma} \varepsilon^{(\alpha \beta \gamma)} \\
& \bar{\sigma}_{i j}=\left\langle\left\langle\sigma_{i j}(x)\right\rangle\right\rangle, \quad \bar{\sigma}=\frac{1}{d h l} \sum_{\alpha=1}^{N_{\alpha}} \sum_{\beta=1}^{N_{\beta}} \sum_{\gamma=1}^{N_{\gamma}} d_{\alpha} h_{\beta} I_{\gamma} \sigma^{(\alpha \beta \gamma)} \\
& \bar{\sigma}_{i j}=C_{i j k l}^{*}\left(\bar{\varepsilon}_{k l}-\bar{\varepsilon}_{k l}^{I}-\bar{\varepsilon}_{k l}^{T}\right), \quad \bar{\sigma}_{i j}=C^{*}\left(\bar{\varepsilon}-\bar{\varepsilon}^{I}-\bar{\varepsilon}^{T}\right) \\
& C_{i j k l}^{*}=\left\langle\left\langle C_{i j r s}(x) A_{r s k l}(x)\right\rangle\right\rangle, \quad C^{*}=\frac{1}{d h l} \sum_{\alpha=1}^{N_{\alpha}} \sum_{\beta=1}^{N_{\beta}} \sum_{\gamma=1}^{N_{\gamma}} d_{\alpha} h_{\beta} l_{\gamma} C^{(\alpha \beta \gamma)} A^{(\alpha \beta \gamma)} \\
& \bar{\varepsilon}_{i j}^{I}=\left\langle\left\langle B_{k l i j}(x) \varepsilon_{k l}^{I}(x)\right\rangle\right\rangle, \\
& \bar{\varepsilon}^{I}=-\frac{1}{d h l}\left(C^{*}\right)^{-1} \sum_{\alpha=1}^{N_{\alpha}} \sum_{\beta=1}^{N_{\beta}} \sum_{\gamma=1}^{N_{\gamma}} d_{\alpha} h_{\beta} l_{\gamma} C^{(\alpha \beta \gamma)}\left(D^{(\alpha \beta \gamma)} \varepsilon_{s}^{I}-\varepsilon^{I(\alpha \beta \gamma)}\right) \\
& \bar{\varepsilon}_{i j}^{T}=\left\langle\left\langle B_{k l i j}(x) \varepsilon_{k l}^{I}(x)\right\rangle\right\rangle, \\
& \bar{\varepsilon}^{T}=-\frac{1}{d h l}\left(C^{*}\right)^{-1} \sum_{\alpha=1}^{N_{\alpha}} \sum_{\beta=1}^{N_{\beta}} \sum_{\gamma=1}^{N_{\gamma}} d_{\alpha} h_{\beta} l_{\gamma} C^{(\alpha \beta \gamma)}\left(D^{(\alpha \beta \gamma)} \varepsilon_{s}^{T}-\varepsilon^{T(\alpha \beta \gamma)}\right)
\end{aligned}
$$

In equations (5) to (10) an overbar indicates a macroscale variable; (x) explicitly indicates that the local variable is a function of position; $\langle\langle\cdot\rangle\rangle=\frac{1}{V} \int_{V} \cdot d V$ is the volume average operator; $\mathrm{C}_{i j k l}^{*}$ denotes the overall effective elastic stiffness tensor; the superscript $(\alpha \beta \gamma)$ refers to subcell $(\alpha \beta \gamma)$ where $\alpha, \beta$, and $\gamma$ are indices in the three coordinate directions; $d, h$, and $l$ are the overall dimensions of the repeating unit cell and the same variables with subscripts denote dimensions of subcells; $A_{i j k l}, B_{i j k l}$, and $D_{i j k l}$ are the elastic strain, stress, and nonelastic strain localization tensors; and $\varepsilon_{s}^{I}$ and $\varepsilon_{s}^{T}$ are arrays containing the subcell inelastic and thermal strain vectors.

GMC has been implemented into the recently developed micromechanics analysis code (MAC/GMC) which has many user friendly features and significant flexibility (Wilt and Arnold, 1996). The GMC unit cell representations utilized herein for square, hexagonal, and square diagonal arrays are shown in figure 7.

\section{III.3. Constituent Models}

As mentioned previously, the fiber response is assumed to be linear elastic and temperature independent $\left(E=400 \mathrm{GPa}, v=0.2, \mathrm{CTE}=3.5 \times 10^{-6}{ }^{\circ} \mathrm{C}^{-1}\right)$. The elastic-viscoplastic behavior of the matrix is represented using a generalized viscoplastic potential structure (GVIPS) model (Arnold et al., 1996b,c). This model is a fully associative, multiaxial, nonisothermal, nonlinear kinematic hardening viscoplastic model for use with initially isotropic metallic materials. A unique aspect of this model is the inclusion of nonlinear hardening through the use of a compliance operator $Q_{i j k l}$ in the evolution law for the back stress. This nonlinear tensorial operator is significant in that it allows both the flow and evolutionary laws to be fully associative and greatly influences the multiaxial response under nonproportional loading paths so prevalent within composite materials. The primary equations are summarized by, 


$$
\begin{array}{lll}
\dot{\varepsilon}_{i j}^{I} & =\lambda \Sigma_{i j} \quad \text { if } \hat{F}>0 & \text { flow law } \\
A_{i j} & =\left\{\begin{array}{ccc}
Q_{i j k l} C_{k l p q} b_{p q} & \text { if } & a_{i j} \Sigma_{i j}<0 \\
b_{i j} & \text { if } & a_{i j} \Sigma_{i j} \geq 0
\end{array}\right. & \text { evolution law } \\
\dot{a}_{i j} & =L_{i j k l}\left(\dot{A}_{k l}-\theta_{k l} \dot{T}\right) &
\end{array}
$$

where

$$
\begin{array}{lr}
\lambda=\sqrt{\frac{\dot{\varepsilon}_{i j}^{I} \dot{\varepsilon}_{i j}^{I}}{2 J_{2}}, \quad J_{2}=\frac{1}{2} \Sigma_{i j} \Sigma_{i j}} & \sum_{i j}=S_{i j}-a_{i j} \\
L_{i j k l}=Q_{i j k l}^{-1}=K_{1}\left(I_{i j k l}+K_{2} a_{i j} a_{k l}\right) & S_{i j}=\sigma_{i j}-\frac{1}{3} \sigma_{k k} \delta_{i j} \\
b_{i j}=\dot{\varepsilon}_{i j}^{I}-K_{3} a_{i j} & a_{i j}=\alpha_{i j}-\frac{1}{3} \alpha_{k k} \delta_{i j} \\
\theta_{i j} K_{4} a_{i j} & \\
\hat{F}=\left\langle\frac{\sqrt{3 J_{2}}}{\kappa}-\hat{Y}\right\rangle, \quad \hat{Y}=\langle 1-\beta \sqrt{\hat{G}}\rangle, \quad G=\frac{3 a_{i j} a_{i j}}{2 \kappa_{0}^{2}}, &
\end{array}
$$

where the Macauley brackets are defined by

$$
\langle x-a\rangle=\left\{\begin{array}{cc}
0 & x<a \\
x-a & x \geq a .
\end{array}\right.
$$

The constants $K_{1}-K_{4}$ contain material parameters and internal stress invariants and can be inferred from Arnold et al. (1996b).

Weak bonding between the fiber and matrix is modeled by assuming that a jump in the displacement field may occur under certain conditions, while the traction vector remains continuous. In this model debonding initiates when the normal traction exceeds a critical value or when the tangential traction exceeds a critical value, with no interaction between the two,

$$
\left.\begin{array}{c}
\dot{u}_{n}=R_{n} \dot{T}_{n} \\
\dot{u}_{t}=R_{t} \dot{T}_{t}
\end{array}\right\} \text { if } T_{n} \geq T_{n}^{c r i t} \text { or } T_{t} \geq T_{t}^{c r i t}
$$

where $u$ denotes interfacial displacement, $T$ the interfacial traction, and $R$ the flexibility of the failed interface. The subscripts $n$ and $t$ denote the directions normal and tangent to the interface respectively. This simple model combines elements of interface models developed by Jones and Whittier (1967) and Achenbach and Zhu (1990). Once debonding has initiated, the interfacial displacement rate is made proportional to the stress rate, simulating a perfectly plastic-like behavior. In the results for $\mathrm{SiC} / \mathrm{Ti}$ with a weak bond the critical normal and tangential tractions have been taken to be 103 and $41.4 \mathrm{MPa}$, respectively, and the flexibility of the failed interface has been taken to be $0.271 \mathrm{~mm} / \mathrm{MPa}$.

\section{STRESS-STRAIN RESPONSE}

Before determining flow surfaces we validated our FEA models by performing a convergence study and comparing stress-strain responses with those published by Brockenbrough et al. (1991) for boron/aluminum. In figure 8, the stress-strain and inelastic power-time responses are shown for axial $\left(\sigma_{11}\right)$, transverse $\left(\sigma_{22}\right)$, and shear $\left(\sigma_{12}\right)$ loadings at $650{ }^{\circ} \mathrm{C}$. Here the effect of microstructure, i.e., square, hexagonal, and square diagonal repeating arrays of 
fibers, is demonstrated using GMC and the unit cells shown in figure 7. Both strong and weak fiber-matrix bonds are considered, but as expected for axial loading the interface does not affect the response. Also as expected, microstructure has no affect on the axial response (fig. 8(a)). Hexagonal and square diagonal array responses for transverse and shear loadings (figs. 8(b) and (c)) for strongly bonded composites are very similar and diverge from the response of a square array for transverse loading, but agree closely with the response of a square array for shear loading. It is clear that the transverse response is strongly affected by microstructural architecture, while the axial and shear responses are not affected and very mildly affected, respectively. However, for weakly bonded composites the square and hexagonal array transverse and shear responses are similar, while the square diagonal array exhibits a more compliant response (figs. 8(b) and (c)).

An accuracy comparison between these GMC unit cell representations and their FEA counter-parts was also undertaken and is described in Appendix B. A summary of our observations based on stress-strain and inelastic power-time responses, relative to the appropriate micromechanics model (FEA and GMC) and microstructural architecture (square, hexagonal, and square diagonal arrays) is as follows:

- GMC predictions agree well with FEA predictions if a fine FEA mesh is employed;

- A fine FEA mesh is required to accurately predict gross inelastic flow in the transverse direction, but for axial and shear loadings a coarse FEA mesh is adequate, however, a coarse mesh appears adequate for any of the loadings considered, provided the inelastic power is small;

- Microstructural architecture is very significant for transverse loading, but has much less effect for axial (none) and shear loading (only significant for weakly bonded composites). Note that we only considered axial shear $\left(\sigma_{12}\right)$ loading, not transverse shear $\left(\sigma_{23}\right)$ loading.

\section{MACROSCALE FLOW/DAMAGE SURFACES}

Our focus now turns to macroscale flow/damage surfaces in order to obtain information on the initial overall dissipation potential. Surfaces of constant inelastic power (SCIPs), defined simply by $\bar{\sigma}_{i j} \dot{\bar{\varepsilon}}_{i j}^{I}$, will be determined in order to give this work relevance to experimental and macroscale continuum approaches. Here the inelastic strain tensor includes matrix inelasticity as well as nonlinear effects associated with fiber-matrix debonding. First, we exercise the FEA models for a strongly bonded composite, then compare FEA and GMC predicted flow surfaces, and then finally consider a weakly bonded composite using GMC.

Consider first the effect that the target value has on SCIPs in the axial-transverse stress plane at $23^{\circ} \mathrm{C}$. Figure 9 shows 1,5 , and $10 \mathrm{kPa} / \mathrm{sec}$ SCIPs for both a square array and a square diagonal array as predicted by the fine and coarse FEA meshes shown in figure 5 for strong bonding. The first observation that we make is that the surfaces for different target values are not concentric for either array and that they are offset in the axial compression direction due to thermal residual stresses. While the surfaces for square and square diagonal arrays are approximately the same size for the same target value, their shapes are different, particularly the $5 \mathrm{kPa} / \mathrm{sec} \mathrm{SCIPs} \mathrm{in} \mathrm{the} \mathrm{first} \mathrm{quadrant}$ (i.e., tension-tension). The $5 \mathrm{kPa} / \mathrm{sec}$ SCIP for a square array has a 'nose' at approximately $35^{\circ}$, while the 'nose' on the same SCIP for a square diagonal array is at approximately $15^{\circ}$. The differences in shapes of the overall flow surfaces are apparently related to the different local stress and strain fields.

Local $J_{2}\left(1 / 2 S_{i j} S_{i j}\right.$, where $S_{i j}$ is the deviatoric Cauchy stress) contours in the matrix are plotted in figure 10 for both arrays given their fine mesh idealizations and all three target values for loading at $35^{\circ}$ from the axial stress axis. The smallest values (darkest) occur in the matrix adjacent to the fiber near the bottom edge (and top edge for the square diagonal array). This is interesting because $J_{2}$ is small where the transverse stress is large and large where the transverse stress is small. Another way to see the differences in the local fields for square and square diagonal arrays is to compare the local stress invariants $I_{1}$ (the sum of the normal stress components) and $J_{2}$. In figure 11, the stress invariants $I_{1}$ and $J_{2}$ for each matrix element have been sorted and are plotted in descending order. Note that while the two arrays each have a fiber volume fraction of 0.35 , the square array has 227 matrix elements in the fine mesh, while the square diagonal array has 281 . The square diagonal array has a relatively small number of elements with large hydrostatic stress, while the square array has a more uniform distribution of hydrostatic stress (fig. 11(a)). For example, the difference between the square and square diagonal arrays for $5 \mathrm{kPa} / \mathrm{sec}$ SCIPs is related to the different $J_{2}$ distributions shown in figure 11(b). The square array has fewer elements with high values of $J_{2}$ and therefore requires a higher overall stress to achieve the same flow target value as the square diagonal array. 
Comparing the SCIPs from the fine and coarse mesh FEAs shown in figure 9 indicates that the coarse mesh for a square array of fibers provides reasonably good results in the axial-transverse stress plane. However, in the case of a square diagonal array of fibers agreement between the fine and coarse mesh results is not as good, implying that too few elements were used in the coarse square diagonal array mesh.

Clearly, it is highly preferable to use a coarse mesh in lieu of a fine mesh, provided the accuracy of the results can be maintained, as the execution time is greatly reduced.

Nimmer et al. (1991) used FEA to study the effect that the aspect ratio of a rectangular array has on the transverse tensile response of a weakly bonded SCS-6/Ti-6-4 composite system. Here we expand the spirit of Nimmer's study to the biaxial loading behavior of a strongly bonded SCS-6/TIMETAL 21S composite system. A wide range of aspect ratios $(R=a / b$ in fig. 1$), 0.5<R<2.0$, are considered and compared with results for a square array $(R=1.0)$. Figure 12 shows $5 \mathrm{kPa} / \mathrm{sec} \mathrm{SCIPs}$ at $23^{\circ} \mathrm{C}$ in four stress planes for aspect ratios of $0.5,1.0$, and 2.0. As demonstrated previously, the microstructural architecture, defined by the aspect ratio here, has the largest effect by far on the transverse response.

One application for the kind of information that flow surfaces provide is the design of components subjected to loads resulting in deterministic multiaxial stress states. The microstructure can then be engineered to best resist the loading. For example, a ring mounted on a shaft in a jet engine will rotate in service. Thus, the radial and circumferential stress components will be tensile. Suppose the ring is to be fabricated from hoop-wound, strongly bonded $\mathrm{SiC} /$ $\mathrm{Ti}$, and that the goal is to delay the onset of inelastic flow as long as possible. According to the first quadrant of the axial-transverse stress plane in figure 12, the largest possible aspect ratio should be used. However, for a weakly bonded composite, once the interface fails the stress distribution is much different because the transverse stress in the fiber gets redistributed to the matrix. In this case, a small aspect ratio is preferred because it provides a long ligament of matrix material between fibers for the transverse stress to flow through, while a large aspect ratio is associated with a short ligament of matrix between fibers and more localized flow (Lissenden and Herakovich, 1996). In figure 13, FEA (coarse mesh) and GMC predicted 1 and $10 \mathrm{kPa} / \mathrm{sec} \mathrm{SCIPs}$ at $23^{\circ} \mathrm{C}$ are compared in all four stress planes for composites with a strong fiber-matrix bond. The SCIPs predicted by FEA and GMC are in good agreement. This is in line with the excellent agreement between yield surfaces defined by local yielding (Mises stress) that Pindera and Aboudi (1988) reported for the method of cells (square packing) and FEA. In figure 13 overall SCIPs are determined based on overall inelastic strain rates and stresses, as might be done in an experiment. These results are in contrast to the FEA/GMC comparisons made in Lissenden and Arnold (1997c), where GMC and FEApredicted flow surfaces were obtained at $650^{\circ} \mathrm{C}$ using strain-controlled and stress-controlled loading, respectively. While initial results indicated that flow surfaces in the axial-transverse stress plane were not very sensitive to whether stress or strain control probing was used (Lissenden et al., 1998); in the transverse-transverse stress plane the control mode is important. Thus, the larger flow surfaces obtained by GMC in strain-control (fig. 8 in Lissenden and Arnold, 1997c) are easily explained. Inelastic deformation is strain rate dependent, thus more deformation occurs for a slower overall strain rate than a faster one. Consequently, in strain control the overall strain rate is fixed, it is the stress rate that decreases as inelastic deformation occurs. However, in stress control the overall strain rate must decrease as inelastic deformation occurs, resulting in more inelastic flow relative to strain control.

Figure 14 shows excellent agreement between GMC and FEA (coarse mesh) $10 \mathrm{kPa} / \mathrm{sec} \mathrm{SCIPs} \mathrm{at} 650{ }^{\circ} \mathrm{C}$ in all four stress planes. The sharp points apparent on some of the surfaces are artifacts due to the large step in probe angle $\left(5^{\circ}\right)$ used to make the analysis less time consuming. These SCIPs are actually smooth curves. SCIPs from finer GMC discretizations having 16 subcells (a cross shaped fiber) and 49 subcells (a roughly circular fiber) were also examined in the axial-transverse stress plane. As was found for FEA (fig. B1), the axial response was independent of the discretization, but the transverse stress was 7 percent less for the 49 subcell model than for the 4 subcell model shown in figure 14. This difference is almost imperceptible at the scale it is drawn. Local stress and strain fields, which ultimately determine the strength or cyclic life of a material, are not reported here, but are the topic of a companion paper (Lissenden et al., 1998).

Consider now, the case of a weak fiber-matrix bond using GMC, which is more realistic for the current SiC/Ti system. In figure $15,1 \mathrm{kPa} / \mathrm{sec}$ SCIPs at $23^{\circ} \mathrm{C}$ for a square array are shown for weak and strong bonds. The primary effect of a weak bond is to significantly reduce the tensile stress at which deviation from proportional response begins. Since compressive interfacial tractions are not detrimental to the integrity of the interface, debonding does not occur for transverse compressive loading (unless it is due to Poisson expansion, see Lissenden and Arnold (1997a)). Additionally, axial loading is not observed to cause debonding.

The effect that microstructural architecture has on $1 \mathrm{kPa} / \mathrm{sec}$ SCIPs in the axial-transverse and transverse-shear stress planes for weakly bonded $\mathrm{SiC} / \mathrm{Ti}$ at $650^{\circ} \mathrm{C}$ is shown in figure 16(a). Microstructural architecture has the most 
influence when a compressive transverse stress is present. As was observed for the stress-strain response (fig. 8), the square array exhibits less inelastic flow than the hexagonal and square diagonal arrays.

Brockenbrough et al. (1991) and Arnold et al. (1996a) demonstrated that as the fiber volume fraction increases, the effect of microstructural architecture increases for uniaxial loadings. Figure 16(b) shows $1 \mathrm{kPa} / \mathrm{sec}$ SCIPs in the axial-transverse stress plane at $650^{\circ} \mathrm{C}$ for square, hexagonal, and square diagonal packings and a fiber volume fraction of 0.50 . The primary effect of increasing the fiber volume fraction is to enlarge the SCIP. Additionally, larger differences in the SCIPs for the three microstructures are observed for the higher fiber volume fraction, especially where the transverse stress is compressive (and the interface has not debonded).

\section{CLOSURE}

Micromechanics has been used to generate overall flow/damage surfaces for unidirectional MMCs having different microstructures. The generalized method of cells results compared very well with those from the computationally more demanding finite element analysis approach, wherein many elements are required to obtain the same level of accuracy. Except for the special case of uniaxial loading in the direction of the fibers, microstructure influ-

ences the shape and location of the macroscale flow/damage surface. The magnitude of the effect that microstructure has on flow/damage surfaces depends strongly on fiber/matrix bond strength, fiber volume fraction, and the type of loading, among other secondary factors. A weak fiber/matrix bond significantly influences the shape of the flow/ damage surface. A dramatic flattening of the surface is observed for transverse tensile loading. Debonding also occurs under shear loadings, but its effect is less drastic.

Flow/damage surfaces are important because multiaxial stress states are encountered in the analysis and design of most structural components due to complex loadings and geometries, as well as due to stress concentrations. The response of MMCs to multiaxial stress states can not be inferred from uniaxial test data. It is necessary to conduct multiaxial tests to guide and later validate theoretical models. To implement the thermodynamically based framework discussed in Section II for a macroscale continuum model, the functional form for the Gibbs and dissipation potentials must be known. Neither of these potentials can be directly determined experimentally. However, one possible approach for continuum model development is to experimentally determine SCIPs in various stress planes and use a micromechanics model to interpret the results. The functional form of the Gibbs and dissipation potentials could then be inferred from the micromechanics model having an inelastic power that correlates well with the experimental results over a wide range of conditions. This work has shown that in addition to the dependence of these potential functions on stress invariants, internal state invariants, and temperature, as for isotropic monolithic materials, they may also depend on directionality, microstructure, and bond strength for MMCs. This adds yet another level of complexity to the macro-based continuum approach for modeling multiaxial inelastic response of MMCs. 


\section{APPENDIX A}

\section{A MACROSCALE CONTINUUM EXAMPLE}

Consider, a unidirectional MMC and smear the microstructure such that we have a homogeneous anisotropic material. Thus, all variables in this appendix refer to composite quantities, there are no local (micro) variables. The effect of hydrostatic stress on the flow of most metals is quite small and usually neglected, as is the case here, even though composites can be dependent upon hydrostatic stresses (e.g., Aboudi, 1991 and Jansson, 1995). Assume that the dissipation potential can be written in terms of two scalar functions, $\Omega=\Omega(F, H)$, where $H$ is a function of the deviatoric internal stress, $a_{i j}$, and the reinforcement direction, defined by $D_{i j}$, and

$$
F=\frac{1}{k_{T}^{2}}\left[I_{1}+\frac{1}{\eta^{2}} I_{2}+\frac{9}{4\left(4 \omega^{2}-1\right)} I_{3}\right]-1
$$

where

$$
\begin{array}{lll}
I_{1}=\left(J_{2}^{3}+c J_{3}^{2}\right)^{1 / 3}-I+\frac{1}{4} I_{3} & I=D_{i j} \Sigma_{j k} \Sigma_{k i} \quad I_{0}=D_{i j} \Sigma_{j i} \\
I_{2}=I-I_{3} & J_{2}=\frac{1}{2} \Sigma_{i j} \Sigma_{j i} & \\
I_{3}=I_{0}^{2} & J_{3}=\frac{1}{3} \Sigma_{i j} \Sigma_{j k} \Sigma_{k i}
\end{array}
$$

and $k_{\mathrm{T}}$ is the transverse shear strength; also, $\eta$ and $\omega$ denote threshold stress ratios for shear and normal loading, respectively. The constant $c$ scales the effect of $J_{3}$ on inelastic flow and must be determined experimentally. This form of $F$ is for transversely isotropic materials and is due to Robinson and Duffy (1990), except here $J_{2}$ has been replaced with Drucker's $(1949) J_{2} / J_{3}$ form $(\mathrm{c}=-9 / 4)$. In this theory, the inelastic strain rate vector is normal to surfaces having constant $F$ in stress space (see eq. (3)). Thus, normality only applies to flow surfaces proportional to surfaces having $F=$ constant. It can be shown that

$$
\sigma_{i j} \dot{\varepsilon}_{i j}^{I}=2(F+1) \frac{\partial \Omega}{\partial F}
$$

in the neighborhood of the virgin state, which are proportional to $F=$ constant surfaces. On the other hand, SCISRs turn out to be

$$
\begin{gathered}
\sqrt{\dot{\varepsilon}_{i j}^{I} \dot{\varepsilon}_{i j}^{I}}=\left(\frac{1}{k_{T}^{2}} \frac{\partial \Omega}{\partial F}\right)\left\{\left(J_{2}^{3}+c J_{3}^{2}\right)^{-4 / 3}\left[2 J_{2}^{5}+4 c J_{2}^{2} J_{3}^{2}\left(1+\frac{2}{27} c\right)\right]\right. \\
+2\left(\frac{1}{\eta^{2}}-1\right)\left(J_{2}^{3}+c J_{3}^{2}\right)^{-2 / 3}\left[J_{2}^{2} \Sigma_{i j}\left(D_{k i} \Sigma_{j k}+D_{j k} \Sigma_{k i}\right)+\frac{2}{3} c J_{3} \Sigma_{i l} \Sigma_{j l}\left(D_{k i} \Sigma_{j k}+D_{j k} \Sigma_{k i}\right)-\frac{8}{9} c J_{2} J_{3} I_{0}\right] \\
+I_{0}\left(1+\frac{4}{\eta^{2}}+\frac{9}{4 \omega^{2}-1}\right)\left[\left(J_{2}^{3}+c J_{3}^{2}\right)^{-2 / 3}\left(I_{0} J_{2}^{2}-\frac{4}{9} c J_{2} J_{3}+\frac{2}{3} c J_{3} D_{i j} \Sigma_{j k} \Sigma_{k i}\right)+\left(\frac{1}{\eta^{2}}-1\right)\left(D_{i j} \Sigma_{j k} D_{k i}+D_{i j} D_{j k} \Sigma_{k i}-\frac{2}{3} I_{0}\right)\right] \\
+\left(\frac{1}{\eta^{2}}-1\right)^{2}\left[\left(D_{k i} \Sigma_{j k}+D_{j k} \Sigma_{k i}\right)\left(D_{l i} \Sigma_{j l}+D_{j l} \Sigma_{l i}\right)+\frac{4}{3} I_{3}\left(I_{0}-2\right)\right] \\
\left.+I_{3}\left(1-\frac{4}{\eta^{2}}+\frac{9}{4 \omega^{2}-1}\right)^{2}\left(D_{i j} D_{i j}-\frac{1}{3}\right)\right\}^{1 / 2}
\end{gathered}
$$


For an isotropic material (that is, $\eta=\omega=1$ ), SCISRs reduce to

$$
\sqrt{\dot{\varepsilon}_{i j}^{I} \dot{\varepsilon}_{i j}^{I}}=\frac{\sqrt{2} J_{2}}{k^{3}(F+1)} \frac{\partial \Omega}{\partial F}\left[(F+1)+\frac{c J_{3}^{2}}{k^{6}(F+1)^{2}}\left(1+\frac{4}{27} c\right)\right]^{1 / 2}
$$

and if the $J_{3}$ contribution to inelastic flow is negligible (that is, $c=0$ ) we get

$$
\sqrt{\dot{\varepsilon}_{i j}^{I} \dot{\varepsilon}_{i j}^{I}}=\frac{\sqrt{2(F+1)}}{k} \frac{\partial \Omega}{\partial F}
$$

Thus, SCISRs are only proportional to surfaces having $F=$ constant for the special case of isotropic $J_{2}$ materials, and therefore the normality criterion only applies to SCISRs for this special class of materials. Also, Lissenden and Arnold (1997a) extrapolated these results to rate-independent plasticity by considering $\sigma_{i j} \varepsilon_{i j}^{I}$ and $\sqrt{\frac{2}{3}} \varepsilon_{i j}^{I} \varepsilon_{i j}^{I}$, where the latter is the usual equivalent inelastic strain definition often used to define a yield surface, and found results analogous to those for SCDRs and SCISRs. Hence, the Nigam et al. (1994a,b) results on boron/aluminum that the plastic strain rate vector was not normal to the yield surface could be merely dependent on their definition of yield. 


\section{APPENDIX B}

\section{A MESH REFINEMENT STUDY}

Here a comparison of the stress-strain responses for uniaxial and biaxial loadings using both FEA and GMC is conducted. Additionally, since we are interested in inelastic power, its increase as a function of time will also be plotted for these loadings. In figure B1 the stress-strain and inelastic power-time responses are shown for axial $\left(\sigma_{11}\right)$, transverse $\left(\sigma_{22}\right)$, and shear $\left(\sigma_{12}\right)$ loadings at $650^{\circ} \mathrm{C}$. A square array of fibers is discretized using the coarse and fine FEA meshes (fig. 5) and the four subcell GMC model (fig. 7). For axial loading the three predictions are nearly identical for both stress-strain and inelastic power (fig. B1(a)), which is not surprising since the material response is dominated by the fiber as evidenced by the high stresses and small inelastic power relative to the other two types of loading. On the other hand, transverse and shear loadings are matrix dominated and differences between analysis techniques are anticipated.

The disparity in the coarse and fine mesh FEA-predicted transverse stress-strain and inelastic power-time responses shown in figure B1(b) indicates that the coarse mesh is not adequate for predicting gross inelastic flow, that is, the coarse mesh has not yet converged. Further refinement of the fine mesh indicated that it had converged for the range of stresses obtained in the surface determinations presented in this paper, but for larger stresses an even more refined mesh would be necessary. The GMC-predicted responses agree very well with the fine mesh FEA predictions for the range of stresses obtained in surface determinations. However, for larger stresses a more accurate geometric representation of the fiber within the repeating unit cell would provide more accurate results, see figure 1 of Arnold et al. 1996a.

The shear responses (fig. B1(c)) from the two FEA meshes are identical, indicating that the coarse mesh has converged for shear loading. The GMC predicted response exhibits more inelastic flow and is in reasonably good agreement with the FEA results. The exponential form of the inelastic power accumulation with time (fig. B1(c)) is a result of the constant stress rate used, which causes the inelastic strain rate to approach infinity as the slope of the stress-strain curve approaches zero.

Stress-strain and inelastic power-time responses calculated utilizing FEA and GMC are shown in figure B2 for proportional biaxial loading of a square array of fibers at $650^{\circ} \mathrm{C}$. The axial-transverse $\left(\sigma_{11}=\sigma_{22}\right)$ response shown in figure B2(a) indicates that each micromechanics approach is equally good for predicting axial response, but that differences are present in the predicted transverse response, which lead to differences in the inelastic power. As for uniaxial transverse loading, the coarse FEA mesh is inadequate for predicting gross inelastic flow while GMC provides a very reasonable approximation of the inelastic flow. Each model is equally good for predicting the transverse-transverse $\left(\sigma_{22}=\sigma_{33}\right)$ response, as shown in figure $\mathrm{B} 2(\mathrm{~b})$ and reasonable agreement is also observed for the axial-shear $\left(\sigma_{11}=\sigma_{12}\right)$ response shown in figure B2(c).

Note that the finely meshed FEA takes a relatively long time to execute compared to that of the coarse FEA mesh (a clock-time ratio of approximately 4:1), and even more so relative to GMC. This lengthy execution time is greatly exacerbated when performing flow surface determinations as at least 72 directions for one surface determination are required. Fortunately, the coarse FEA mesh is reasonably accurate for small values of inelastic power, approximately $10 \mathrm{kPa} / \mathrm{sec}$ and below. Thus, it appears acceptable to use the coarse mesh for surface determinations using transverse stresses provided the target value is small. Additionally, GMC, which is numerically more efficient than either FEA model, agrees well with the fine meshed FEA results. 


\section{REFERENCES}

Aboudi, J. (1991), Mechanics of Composite Materials: a unified micromechanical approach, Elsevier, Amsterdam.

Aboudi, J. (1995), Micromechanical analysis of thermo-inelastic multiphase short-fiber composites. Composites Eng. 5, 839.

Achenbach, J.D. and Zhu, H. (1990), Effect of interphases on micro and macromechanical behavior of hexagonalarray fiber composites. J. Appl. Mech. 57, 956.

Arnold, S.M. and Saleeb, A.F. (1994), On the thermodynamic framework of generalized coupled thermoelasticviscoplastic-damage modeling. Int. J. Plasticity 10, 263.

Arnold, S.M. and Castelli, M.G. (1995), What constitutes a model material? HITEMP Review 1995, Volume II: Compressor/Turbine Materials, NASA CP-10178, pp. 35A:1-18

Arnold, S.M., Pindera, M-J., and Wilt, T.E. (1996a), Influence of fiber architecture on the inelastic response of metal matrix composites. Int. J. Plasticity 12, 507.

Arnold, S.M., Saleeb, A.F., and Castelli, M.G. (1996b) ,A fully associative, nonisothermal, nonlinear kinematic, unified viscoplastic model for titanium based matrices. In Thermomechanical Fatigue Behavior of Materials: Second Volume, eds. M.J. Verrilli and M.G. Castelli, pp. 146-173. ASTM-STP 1263, American Society for Testing and Materials, Philadelphia.

Arnold, S.M., Saleeb, A.F., and Castelli, M.G. (1996c), A fully associative, nonlinear kinematic, unified viscoplastic model for titanium based matrices. In Life Prediction Methodology for Titanium Matrix Composites, eds. W.S. Johnson, J.M. Larsen, and B.N. Cox, pp. 231-256. ASTM-STP 1253, American Society for Testing and Materials, Philadelphia.

Brockenbrough, J.R., Suresh, S. and Wienecke, H.A. (1991), Deformation of metal-matrix composites with continuous fibers: geometrical effects of fiber distribution and shape. Acta Metall. Mater. 39, 735.

Clinard, J.A. and Lacombe, C. (1988), Determination of multiaxial flow surfaces at elevated temperatures using the concept of dissipation potential. ORNL TM-10787, Oak Ridge National Laboratory, Oak Ridge.

Drucker, D.C. (1949), Relation of experiments to mathematical theories of plasticity. J. Appl. Mech., 16, A349.

Dvorak, G.J. (1991), Plasticity theories for fibrous composite materials. In Metal Matrix Composites: Mechanisms and Properties, eds. R.K. Everett and R.J. Arsenault, pp. 1-77. Academic Press, San Diego.

HKS (1995), ABAQUS/Standard User's Manual Version 5.5. Hibbitt, Karlsson, and Sorensen, Inc., Pawtucket.

Jansson, S. (1995), Non-linear constitutive equations for strongly bonded fibre-reinforced metal matrix composites. Composites 26, 415.

Jones, J.P. and Whittier, J.S. (1967), Waves at a flexibly bonded interface. J. Appl. Mech. 34, 905.

Lissenden, C.J. and Arnold, S.M. (1997a), Theoretical and experimental considerations in representing macroscale flow/damage surfaces for metal matrix composites. Int. J. Plasticity 13, 327.

Lissenden, C.J. and Arnold, S.M. (1997b), Factors influencing inelastic flow under multiaxial stress states: a perspective of their importance to composites. In HITEMP Review 1997 Advanced High Temperature Engine Materials Technology Program, NASA CP-10192, NASA Lewis Research Center, Cleveland, Paper No. 38.

Lissenden, C.J. and Arnold S.M. (1997c), Effect of microstructural architecture on flow/damage surfaces for metal matrix composites. In Damage Mechanics in Engineering Materials, eds. G.Z. Voyadjis, D.H. Allen, and J.W. Ju, Elsevier, in print.

Lissenden, C.J. and Herakovich, C.T. (1995), Numerical modelling of damage development and viscoplasticity in metal matrix composites. Comput. Methods Appl. Mech. Engng. 126, 289.

Lissenden, C.J. and Herakovich, C.T. (1996), Interfacial debonding in laminated titanium matrix composites. Mech of Materials 22, 279.

Lissenden, C.J., Iyer. S.K., and Arnold, S.M. (1998), Local and overall flow surfaces for composites predicted by micromechanics. In preparation.

Nigam, H., Dvorak, G.J. and Bahei-El-Din, Y.A. (1994b), An experimental investigation of elastic-plastic behavior of a fibrous boron-aluminum composite: I. matrix-dominated mode. Int. J. Plasticity, 10, 23.

Nigam, H., Dvorak, G.J. and Bahei-El-Din, Y.A. (1994b), An experimental investigation of elastic-plastic behavior of a fibrous boron-aluminum composite: II. fiber-dominated mode. Int. J. Plasticity, 10, 49.

Nimmer, R.P., Bankert, R.J., Russel, E.S., Smith, G.A., and Wright, P.K. (1991), Micromechanical modeling of fiber/matrix interface effects in transversely loaded SiC/Ti-6-4 metal matrix composites. J. Comp. Tech. Res. 13,3 . 
Paley, M. and Aboudi, J. (1992), Micromechanical analysis of composites by the generalized cells model. Mech. Mater. 14, 127.

Pindera, M-J. and Aboudi, J. (1988), Micromechanical analysis of yielding of metal matrix composites. Int. J. Plasticity 4, 195.

Robinson, D.N. and Duffy, S.F. (1990), Continuum deformation theory for high-temperature metallic composites. $J$. Eng. Mech. 116, 832.

Robinson, D.N. and Ellis, J.R. (1986), A multiaxial theory of viscoplasticity for isotropic materials. In Proc. Turbine Engine Hot Section Technology, NASA CP-2444, NASA Lewis Research Center, Cleveland, pp. $283-292$.

Suquet, P. (1987), Elements of homogenization for inelastic solid mechanics. In Homogenization techniques for Composite Materials, eds. E. Sanchez-Palencia and A. Zaoui, pp. 193-278. Springer-Verlag, Berlin.

Wilt, T.E. and Arnold, S.M. (1996) Micromechanics analysis code (MAC) User Guide: version 2.0.NASA TM-107290, NASA Lewis Research Center, Cleveland.

TABLE I.-LOCATION AND DIRECTION OF APPLIED

$$
\text { NODAL FORCES }
$$

\begin{tabular}{|l|c|c|c|}
\hline & Top edge & Right edge & Common node \\
\hline Axial, $\sigma_{11}$ & -- & -- & 1 -direction \\
Transverse, $\sigma_{22}$ & -- & 2 -direction & -- \\
Transverse, $\sigma_{33}$ & 3-direction & -- & -- \\
Shear, $\sigma_{12}$ & -- & 1-direction & -- \\
\hline
\end{tabular}

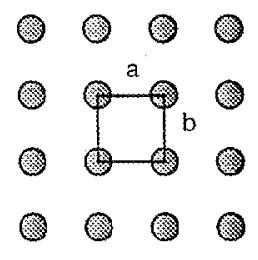

Rectangular Array

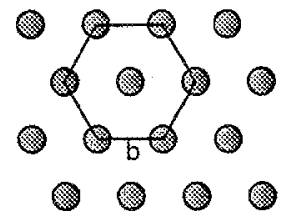

Hexagonal Array

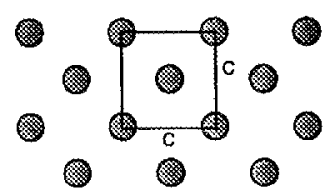

Square Diagonal Array

Figure 1.-Periodic microstrctures; (a) rectangular, (b) hexagonal, and (c) square diagonal array.

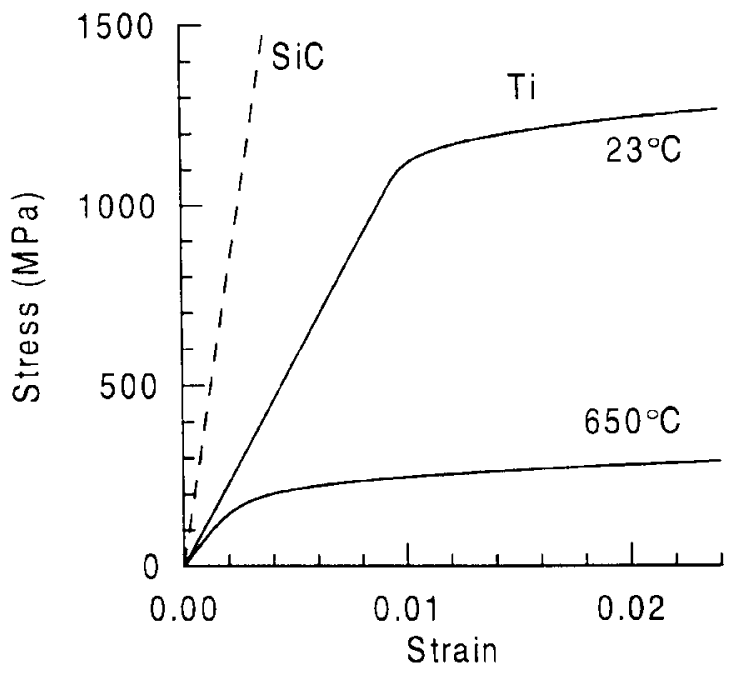

Figure 2.-Predicted constituent response for SiC fiber and Ti matrix. 


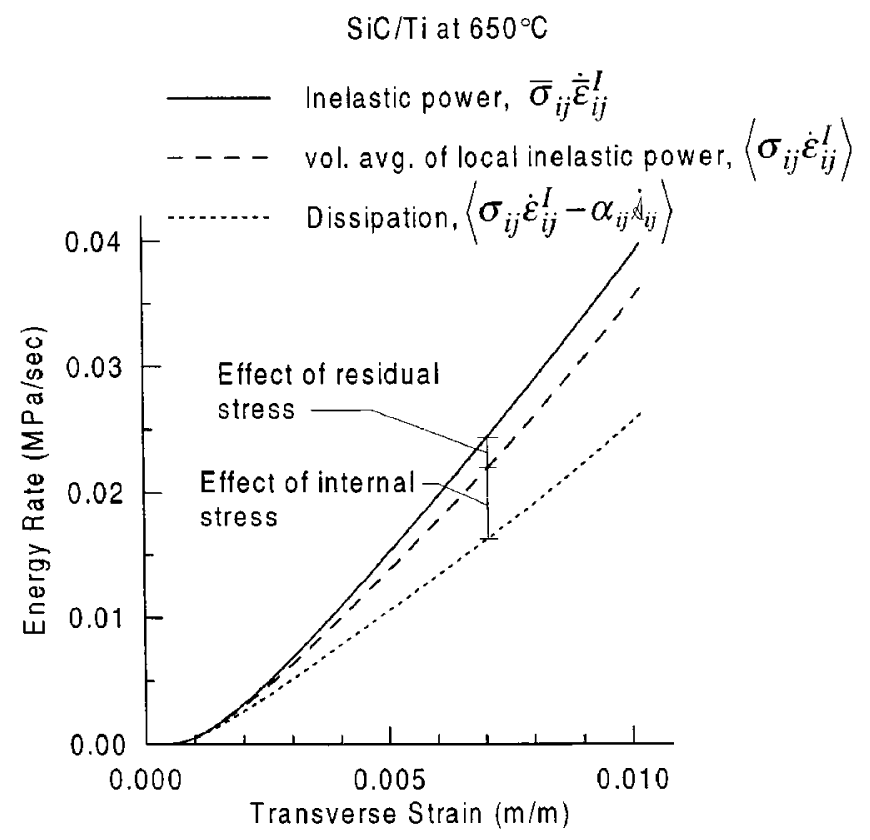

Figure 3.-Inelastic power and dissipation for transverse tensile loading.

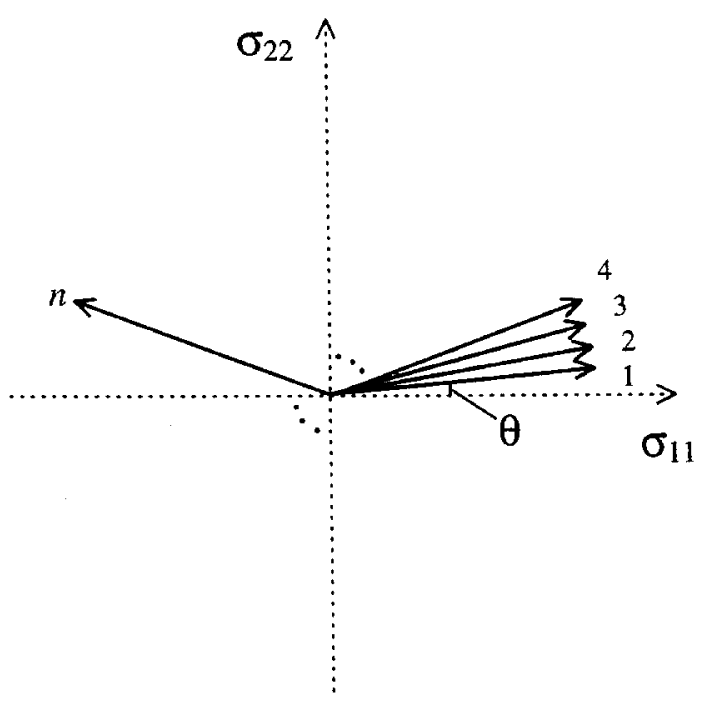

Figure 4.-Flow surface probes. 


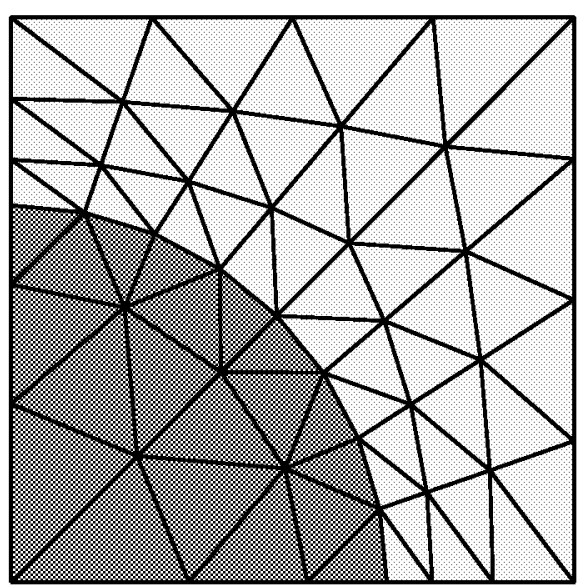

Square array (coarse mesh)

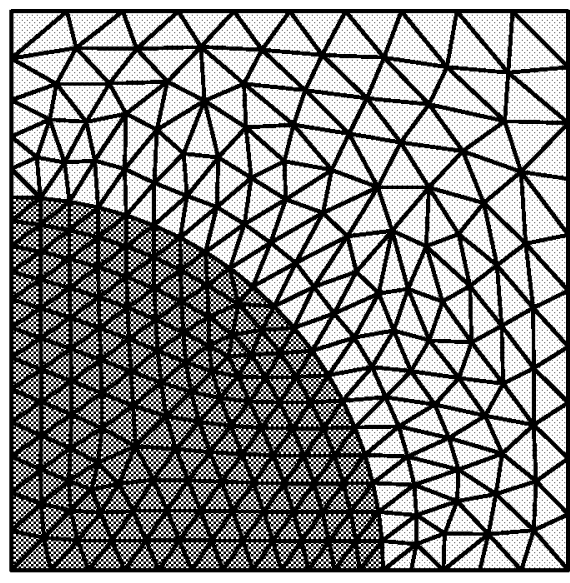

Square array (fine mesh)

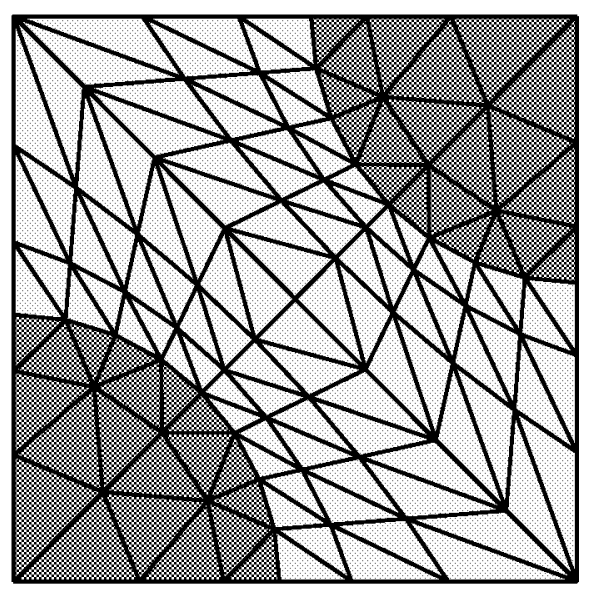

Square diagonal array (coarse mesh)

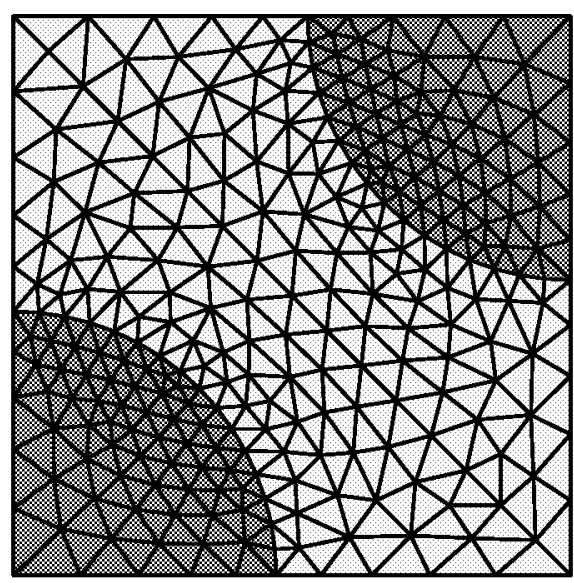

Square diagonal array (fine mesh)

Figure 5.-Coarse and fine mesh FEA discretizations of the rectanglar, hexagonal, and square diagonal microstructures. 


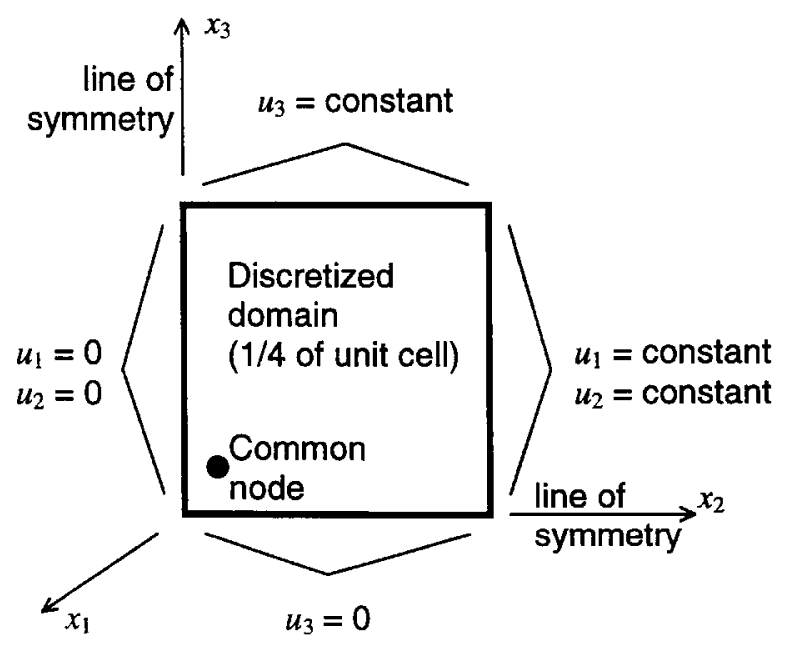

Figure 6.-Boundary conditions for FEA.
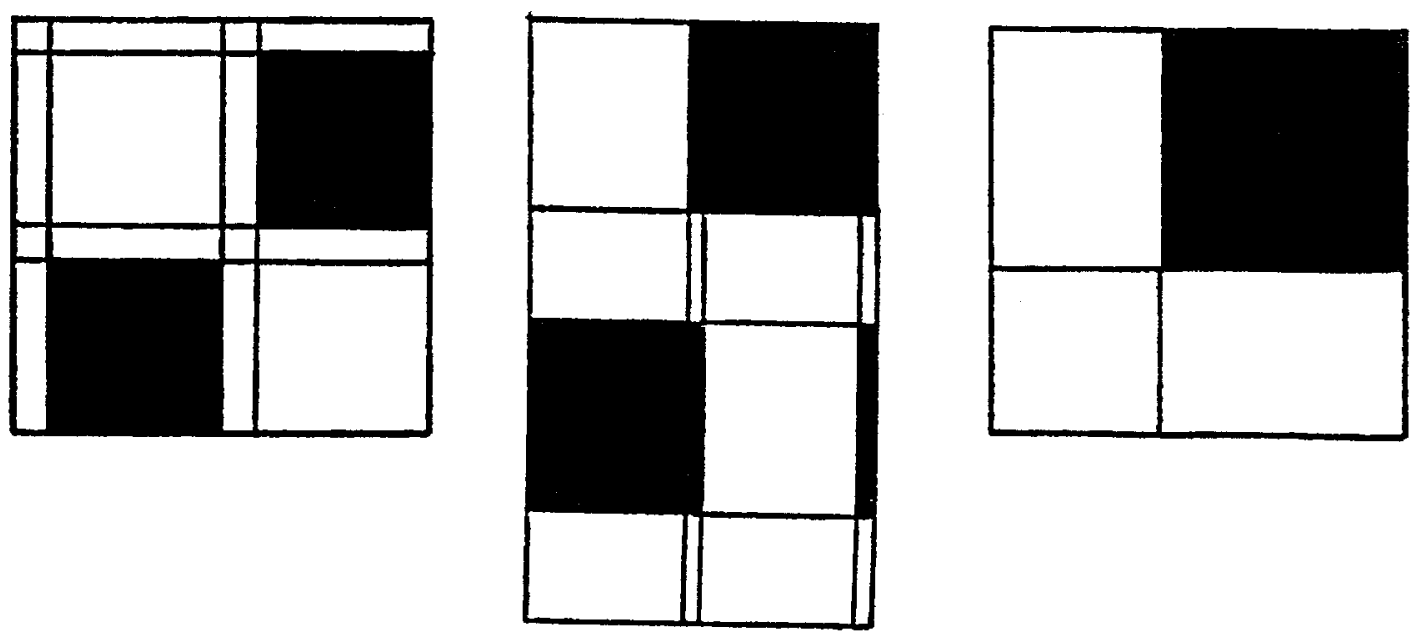

Figure 7.-GMC discretizations of the rectanglar, hexagonal, and square diagonal microstructures. 

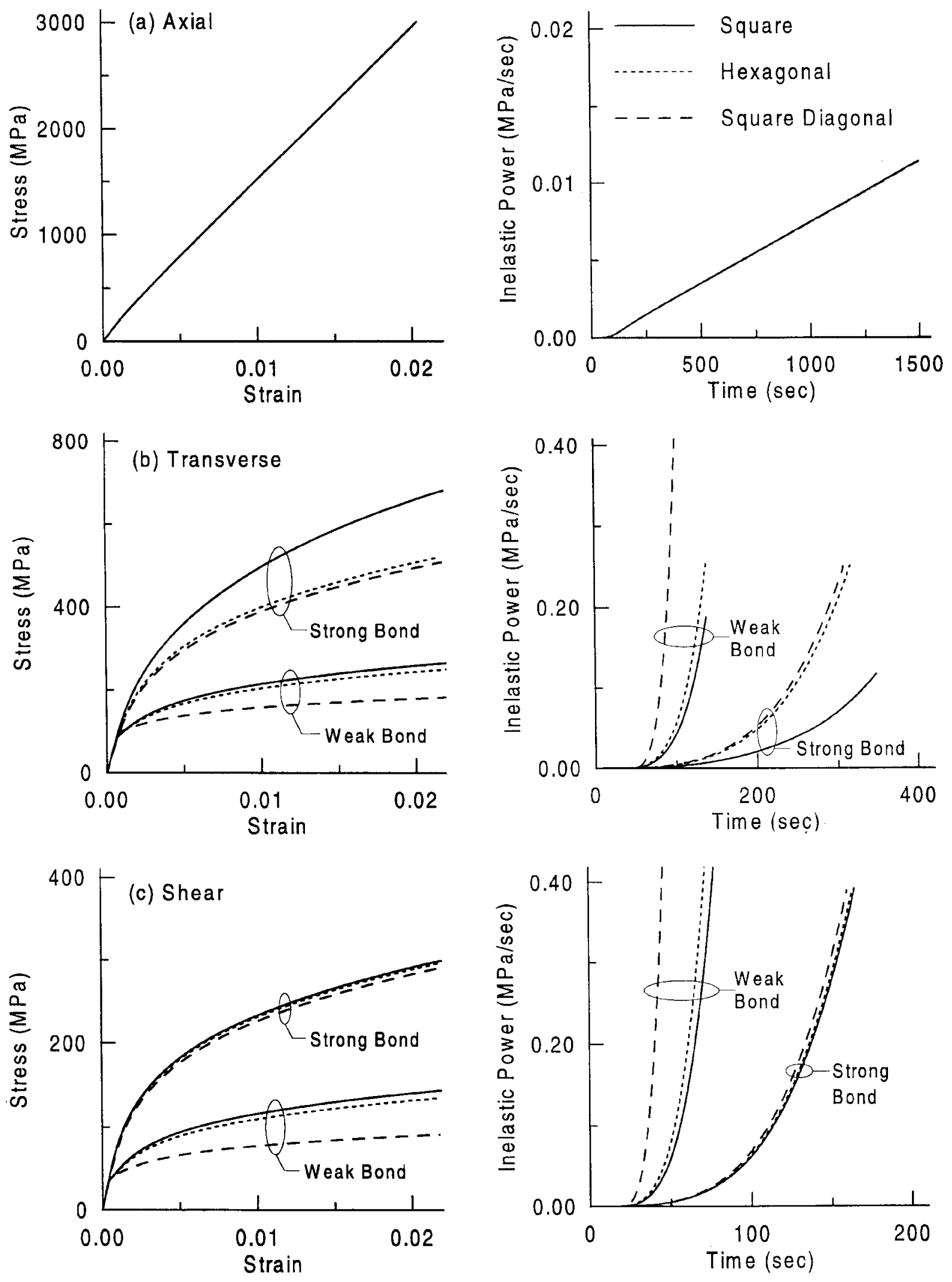

Figure 8.-Uniaxial stress-strain and inelastic power-time responses at $650{ }^{\circ} \mathrm{C}$ for square, hexagonal, and square diagonal arrays from GMC. 

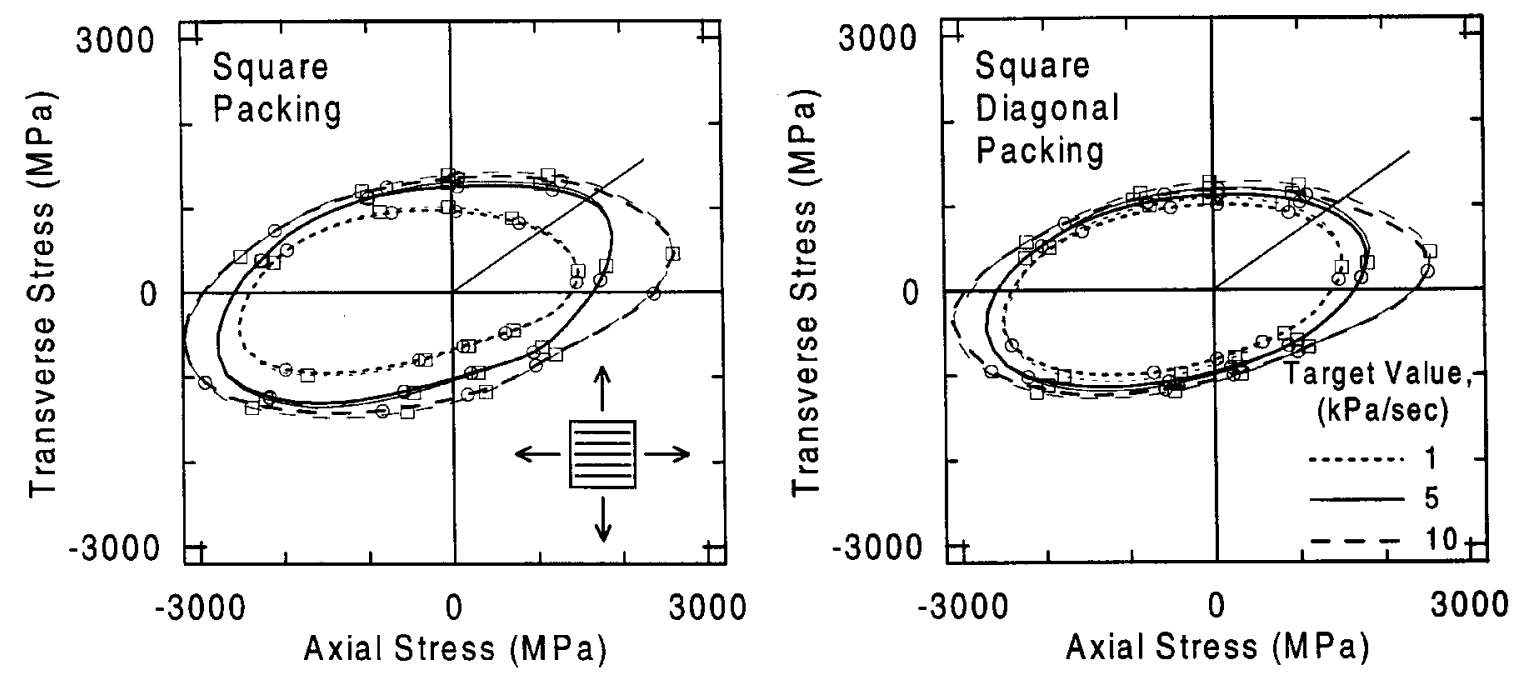

Figure 9.-Effect of target value on SCIPs at $23^{\circ} \mathrm{C}$ in the axial-transverse stress plane for square and square diagonal arrays discretized with fine (dark lines and 0 ) and coarse (light lines and $\square$ ) FEA meshes.
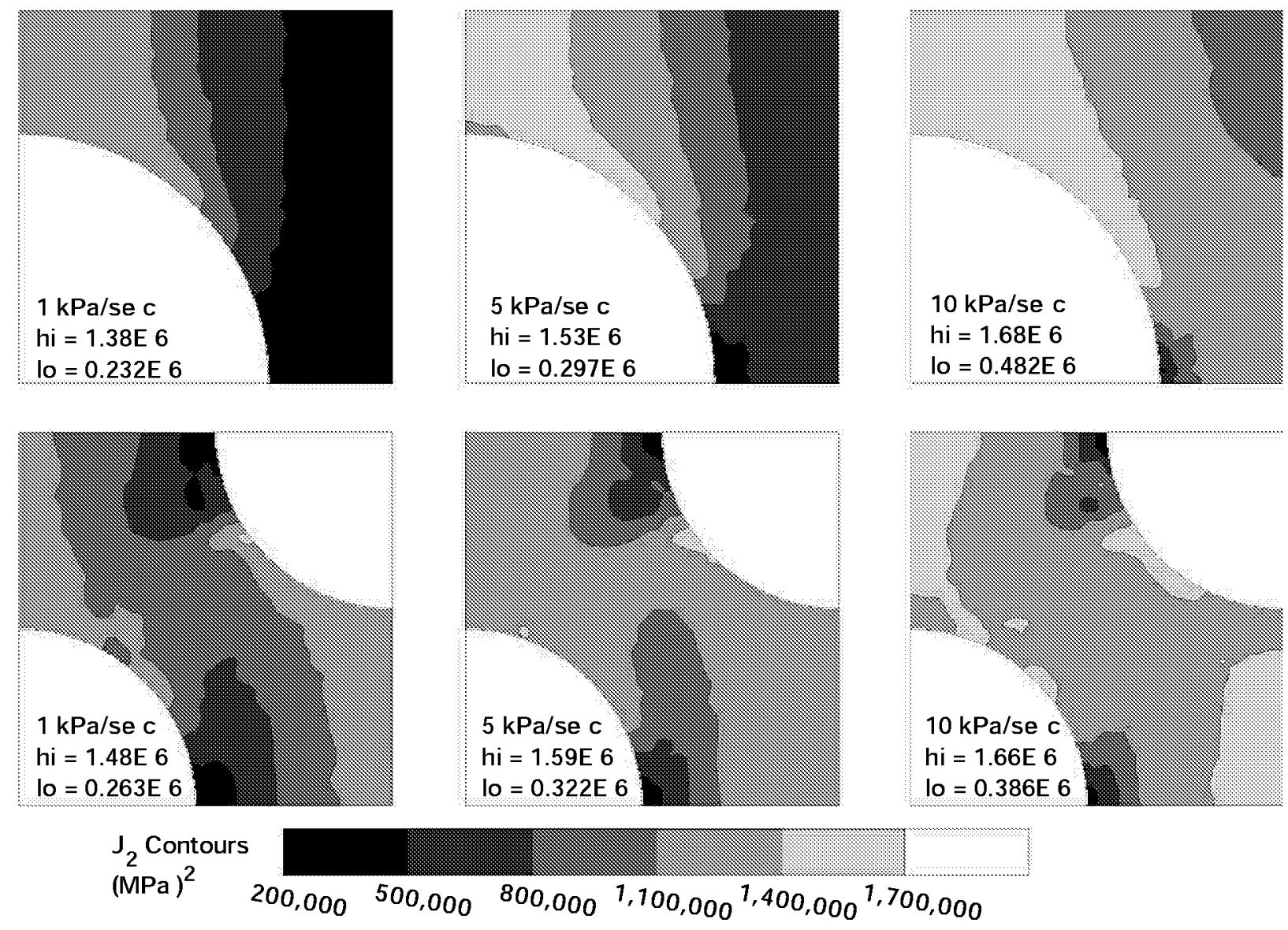

Figure 10.-Matrix $\mathrm{J}_{2}$ contours for a probe angle of $35^{\circ}$ in the axial-transverse stress plane for square and square diagonal arrays and SCIP target values of 1,5 , and $10 \mathrm{kPa} / \mathrm{sec}$. 

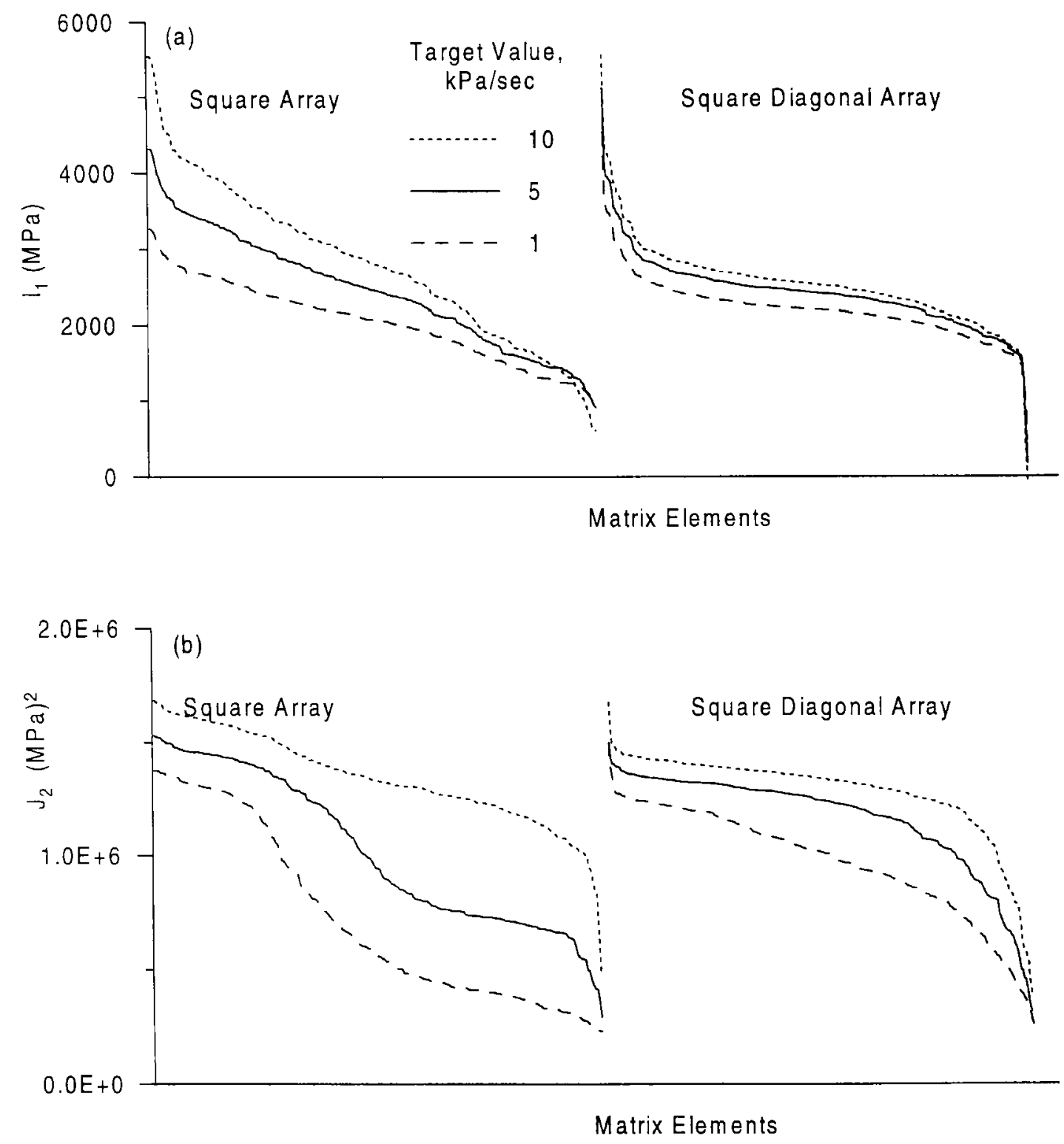

Figure 11.-Sorted distribution (maximum to minimum) of (a) $I_{1}$ and (b) $J_{2}$ in the matrix for a probe angle of $35^{\circ}$ in the axial-transverse stress plane for square and square diagonal arrays and SCIP target values of 1,5 , and $10 \mathrm{kPa} / \mathrm{sec}$. 

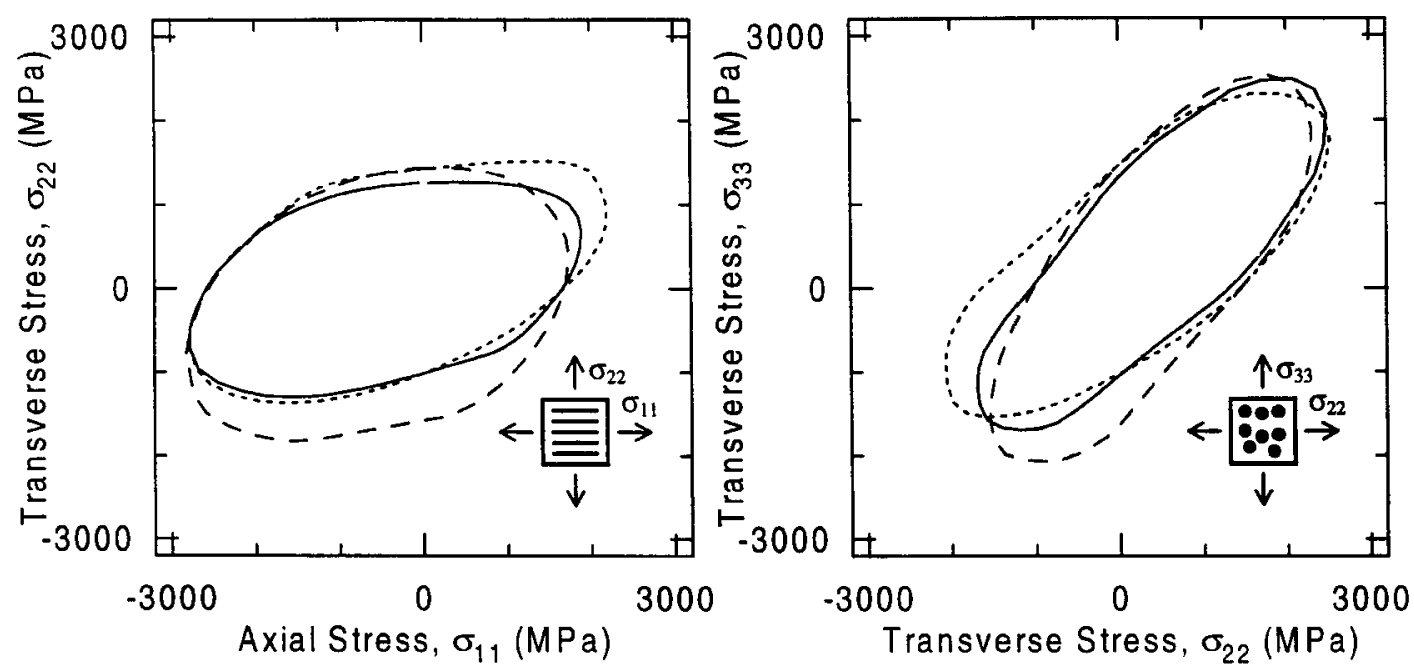

Aspect Ratio, $R$
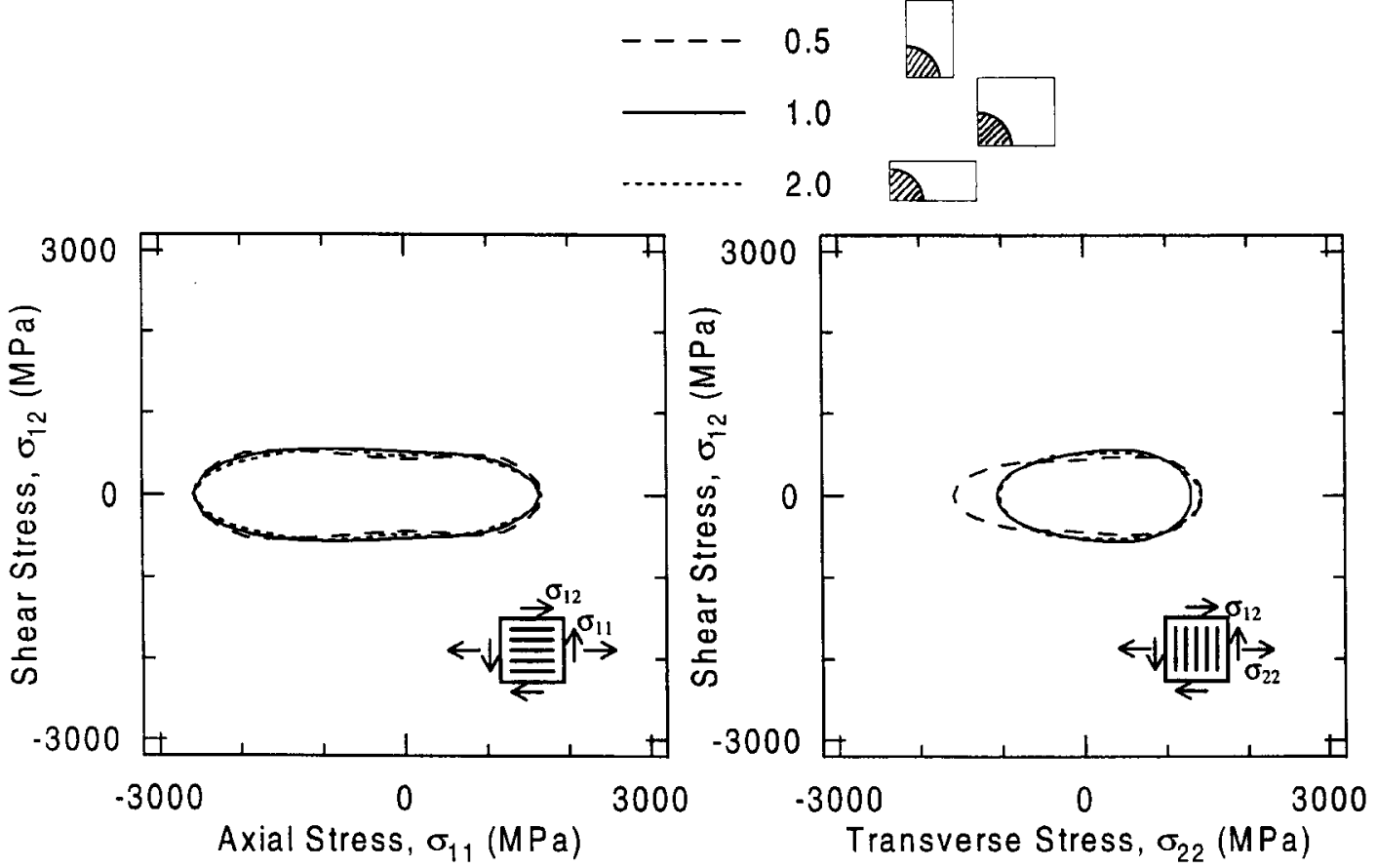

Figure 12.-Effect of aspect ratio on $5 \mathrm{kPa} / \mathrm{sec} \mathrm{SCIPs}$ predicted by $\mathrm{FEA}$ (fine mesh) at $23^{\circ} \mathrm{C}$ for a rectangular array. 

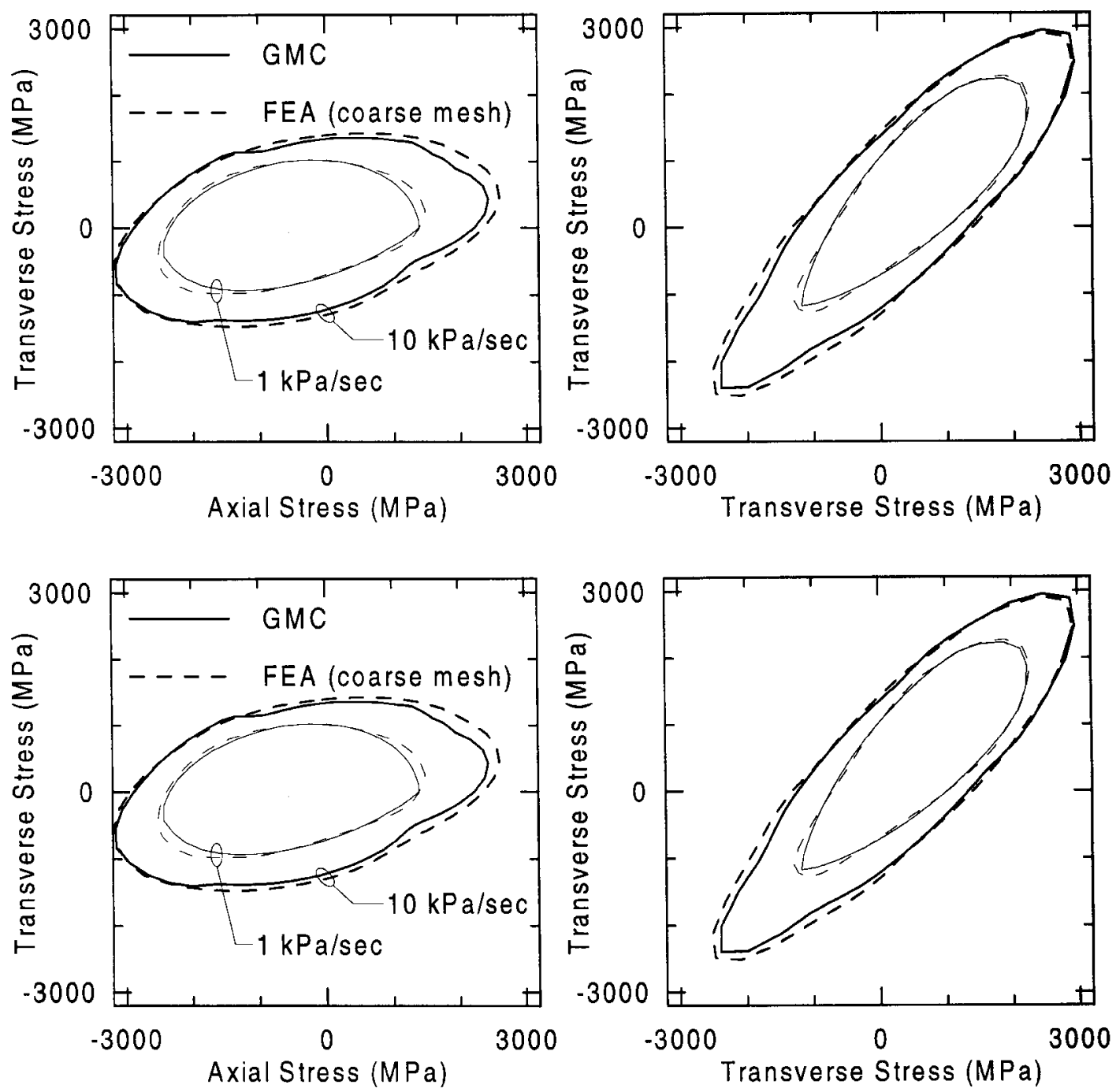

Figure 13.-Comparison of 1 and $10 \mathrm{kPa} / \mathrm{sec}$ SCIPs predicted by GMC and FEA (coarse mesh) at $23^{\circ} \mathrm{C}$ for a square array. 

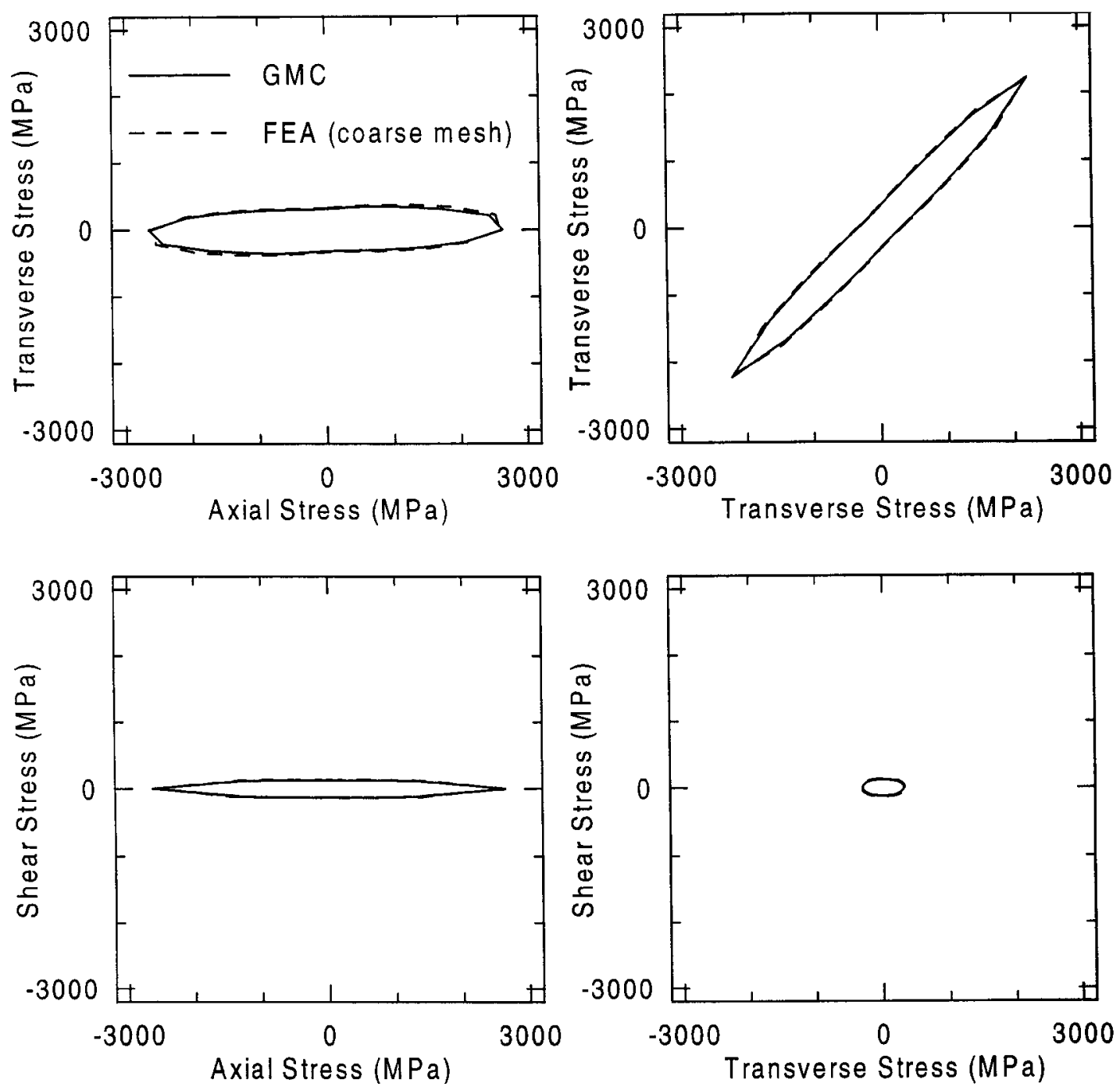

Figure 14.-Comparison of $10 \mathrm{kPa} / \mathrm{sec}$ SCIPs predicted by GMC and FEA (coarse mesh) at $650{ }^{\circ} \mathrm{C}$ for a square array. 

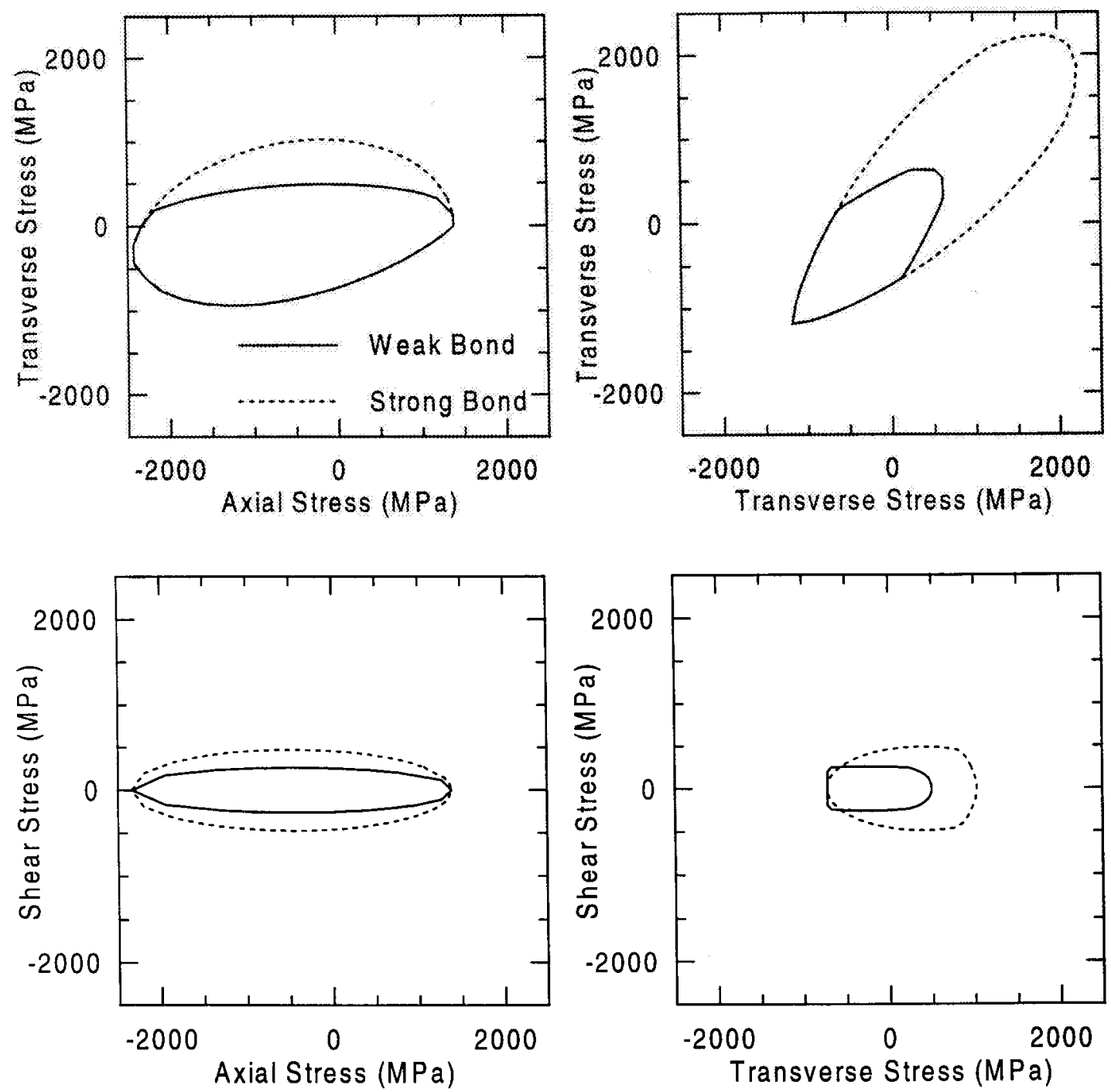

Figure 15.-Effect of debonding on $1 \mathrm{kPa} / \mathrm{sec}$ SCIPs predicted by GMC at $23^{\circ} \mathrm{C}$ for a square array. 

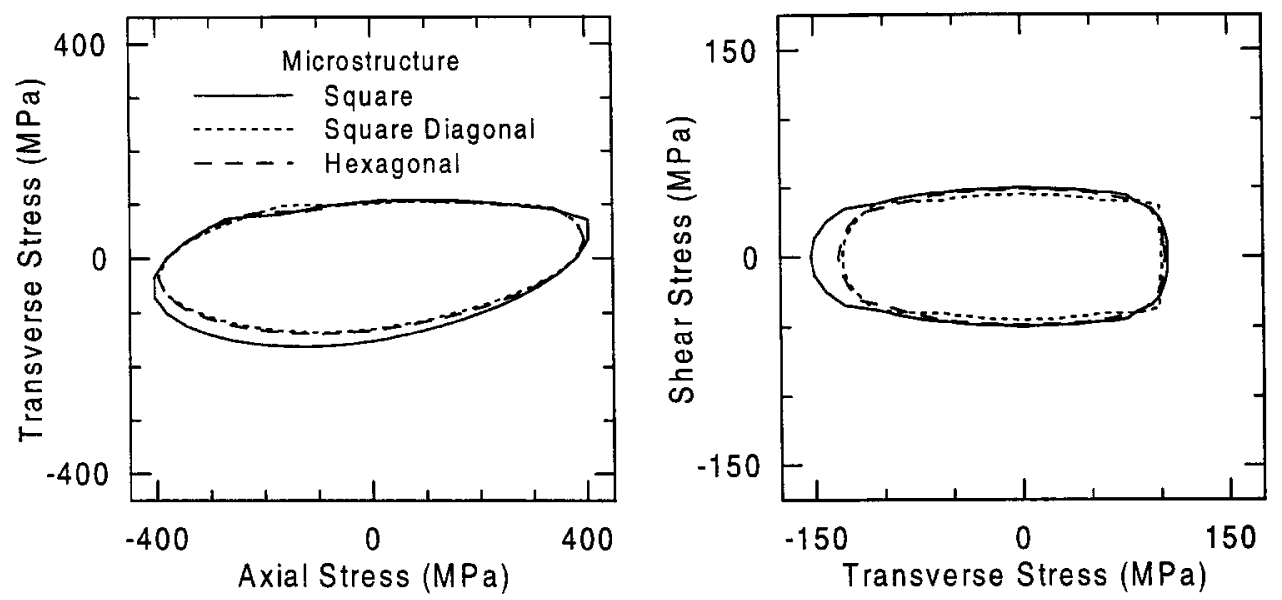

(a) $35 \%$ Fiber
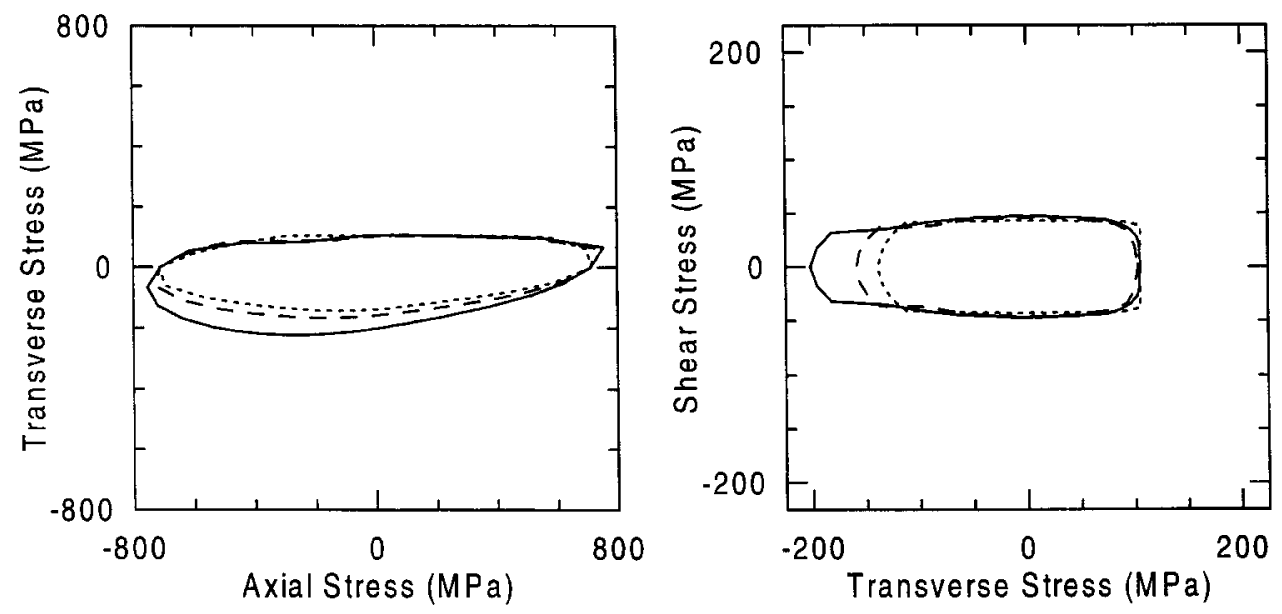

(b) $50 \%$ Fiber

Figure 16.-Effect of microstructure and fiber volume fractron on $1 \mathrm{kPa} / \mathrm{sec}$ SCIPs predicted by $\mathrm{GMC}$ at $650^{\circ} \mathrm{C}$ given weak fiber-marix interface. 

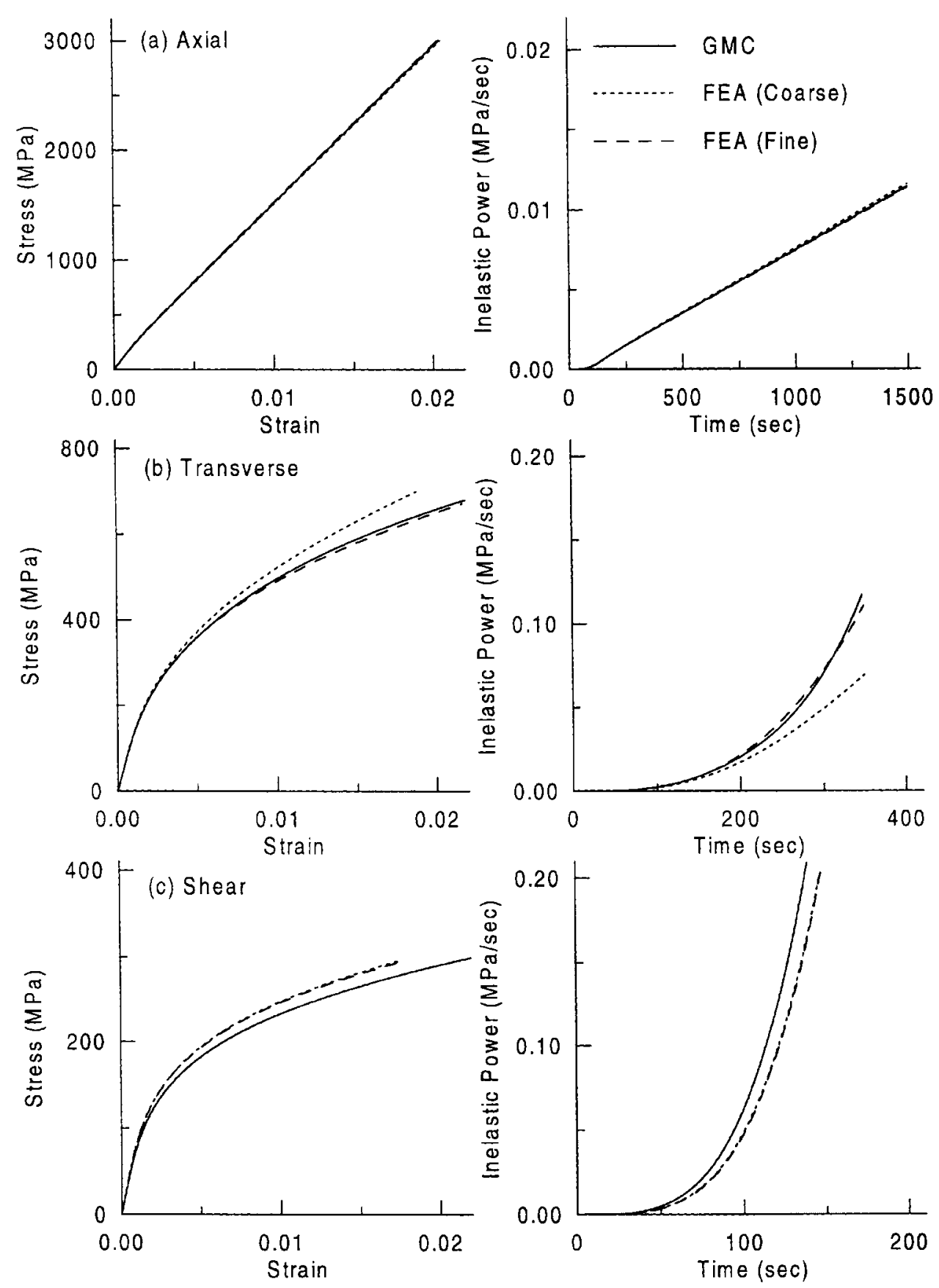

Figure B1.-Uniaxial stress-strain and inelastic power-time responses at $650^{\circ} \mathrm{C}$ for a square array using a coarse mesh FEA, a fine mesh FEA, and GMC. 

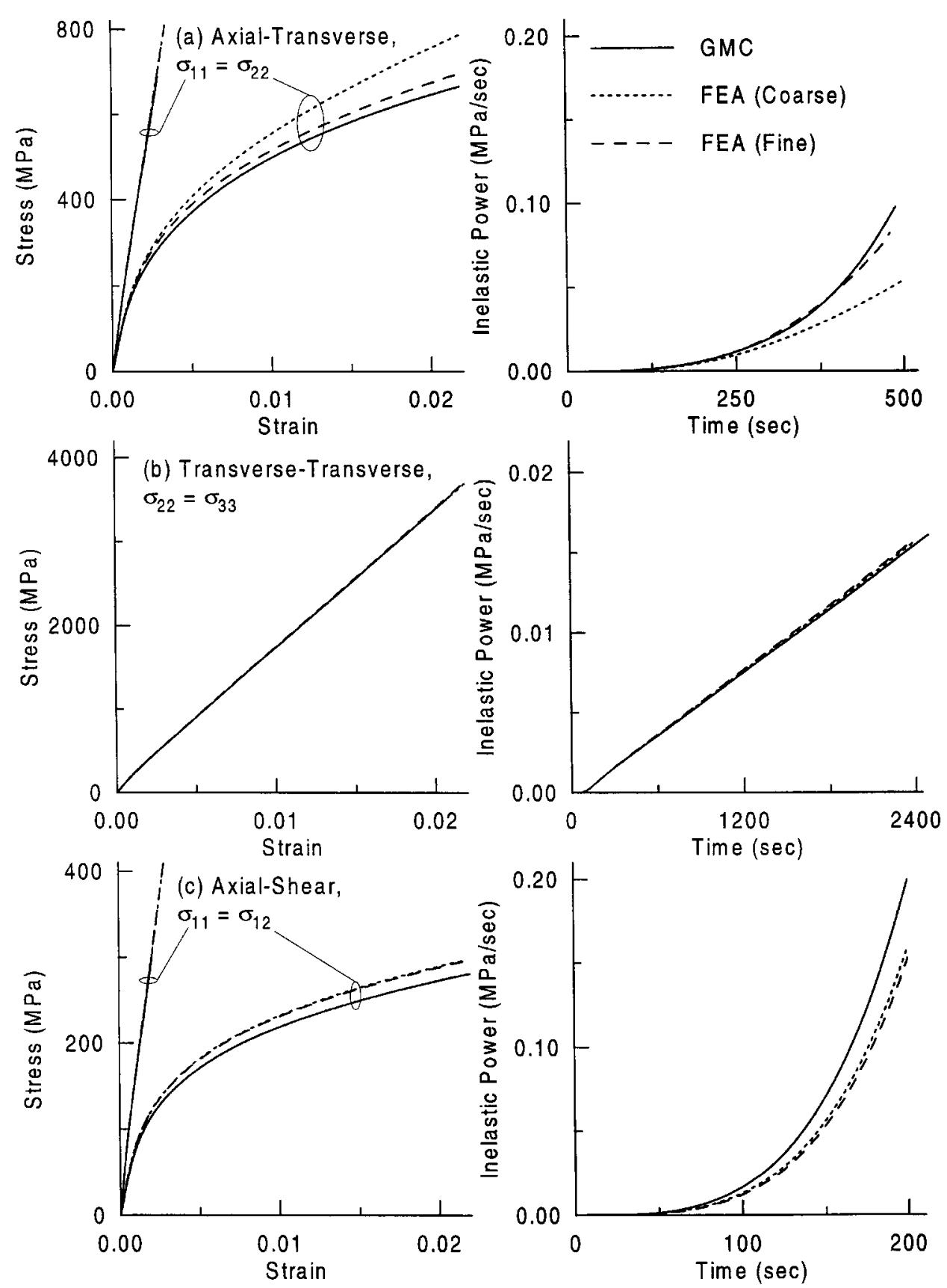

Figure B2.-Biaxial stress-strain and inelastic power-time responses at $650^{\circ} \mathrm{C}$ for a square array using a coarse mesh FEA, a fine mesh FEA, and GMC. 
Public reporting burden for this collection of information is estimated to average 1 hour per response, including the time for reviewing instructions, searching existing data sources, gathering and maintaining the data needed, and completing and reviewing the collection of information. Send comments regarding this burden estimate or any other aspect of this collection of information, including suggestions for reducing this burden, to Washington Headquarters Services, Directorate for Information Operations and Reports, 1215 Jefferson Davis Highway, Suite 1204, Arlington, VA 22202-4302, and to the Office of Management and Budget, Paperwork Reduction Project (0704-0188), Washington, DC 20503.

\begin{tabular}{|l|l|l}
\hline 1. AGENCY USE ONLY (Leave blank) & $\begin{array}{c}\text { 2. REPORT DATE } \\
\text { November } 1998\end{array}$ & $\begin{array}{r}\text { 3. REPORT TYPE AND DATES COVERED } \\
\text { Technical Memorandum }\end{array}$ \\
\hline
\end{tabular}

4. TITLE AND SUBTITLE 5. FUNDING NUMBERS

Flow/Damage Surfaces for Fiber-Reinforced Metals Having Different

Periodic Microstructures

6. AUTHOR(S)

WU-523-21-13-00

Cliff J. Lissenden, Steven M. Arnold, and Saiganesh K. Iyer

7. PERFORMING ORGANIZATION NAME(S) AND ADDRESS(ES)

National Aeronautics and Space Administration

Lewis Research Center

Cleveland, Ohio 44135-3191

8. PERFORMING ORGANIZATION

REPORT NUMBER

E-11389

9. SPONSORING/MONITORING AGENCY NAME(S) AND ADDRESS(ES)

National Aeronautics and Space Administration

Washington, DC 20546-0001

10. SPONSORING/MONITORING

AGENCY REPORT NUMBER

NASA TM-1998-208805

11. SUPPLEMENTARY NOTES

Cliff J. Lissenden and Saiganesh K. Iyer, Pennsylvania State University, University Park, Pennsylvania 16802.

Steven M. Arnold, NASA Lewis Research Center. Responsible person, Steven M. Arnold, organization code 5920 , (216) 433-3334.

12a. DISTRIBUTION/AVAILABILITY STATEMENT

12b. DISTRIBUTION CODE

Unclassified - Unlimited

Subject Categories: 24 and 39

Distribution: Nonstandard

This publication is available from the NASA Center for AeroSpace Information, (301) 621-0390.

13. ABSTRACT (Maximum 200 words)

Flow/damage surfaces can be defined in terms of stress, inelastic strain rate, and internal variables using a thermodynamics framework. A macroscale definition relevant to thermodynamics and usable in an experimental program is employed to map out surfaces of constant inelastic power in various stress planes. The inelastic flow of a model silicon carbide/ titanium composite system having rectangular, hexagonal, and square diagonal fiber packing arrays subjected to biaxial stresses is quantified by flow/damage surfaces that are determined numerically from micromechanics, using both finite element analysis and the generalized method of cells. Residual stresses from processing are explicitly included and damage in the form of fiber-matrix debonding under transverse tensile and/or shear loading is represented by a simple interface model. The influence of microstructural architecture is largest whenever fiber-matrix debonding is not an issue; for example in the presence of transverse compressive stresses. Additionally, as the fiber volume fraction increases, so does the effect of microstructural architecture. With regard to the micromechanics analysis, the overall inelastic flow predicted by the generalized method of cells is in excellent agreement with that predicted using a large number of displacement-based finite elements.

\section{SUBJECT TERMS}

Metal matrix composites; Inelastic; Yield surfaces; Microstructure; Micromechanics

\begin{tabular}{|c|c|c|}
\hline $\begin{array}{c}\text { 17. SECURITY CLASSIFICATION } \\
\text { OF REPORT } \\
\text { Unclassified }\end{array}$ & $\begin{array}{c}\text { 18. SECURITY CLASSIFICATION } \\
\text { OF THIS PAGE } \\
\text { Unclassified }\end{array}$ & $\begin{array}{c}\text { 19. SECURITY CLASSIFICATION } \\
\text { OF ABSTRACT } \\
\text { Unclassified }\end{array}$ \\
\hline
\end{tabular}

